\title{
Testing Collocational Knowledge of Taif University English Seniors
}

\author{
${ }^{1}$ Prof Hassan El-Banna M Gaballa, Dr. Mohmed A Al-Khayri ${ }^{2}$ \\ ${ }^{12}$,Vice Presidency for Higher Studies \& Academic Research \\ \& Dean of Information Technology, Taif University
}

\begin{abstract}
Although it is widely acknowledged that collocations play an important role in the field of second language acquisition, a number of previous studies have reported students' lack of collocational competence and the difficulties they encounter in learning and using collocations. The present study examines the productive and receptive knowledge of lexical and grammatical collocations among advanced Arabic-speaking learners of English. Furthermore, it investigates whether the language environment, i.e., English as a Foreign Language, has an influence on the acquisition of collocations. It also explores whether there is a significant difference between participants' performance on three types of collocations: verb-noun, adjective-noun, and verbpreposition.

Data for this study were collected from sixty-eight participants: thirty-eight Saudi senior female students at the Department of Foreign Languages, Faculty of Arts, Taif University Saudi Arabia in the female campus, and thirty male seniors. The participants' productive collocational knowledge was measured by three gap-filling tests: verb-noun and adjective-noun collocation tests where the initial letter of the collocant was provided and a verb-preposition collocation test where the meaning of the phrasal verb was supplied. Their receptive collocational knowledge was measured by an appropriateness judgment test in which participants have to circle the number corresponding to the underlined part of a sentence that is judged unacceptable.

The results of the statistical analysis revealed that participants' learning environment has a strong effect on the acquisition of L2 collocations. The ESL learners had significantly higher scores than the EFL learners. Moreover, there was a significant difference between the participants' productive and receptive knowledge of collocations. The participants' productive knowledge of collocations lagged far behind their receptive collocational knowledge. The findings also revealed a statistically significant difference between the three types of collocation. The participants performed far better on the verb-noun collocations test than on the adjectivenoun and verb-preposition collocations tests. Overall, the results showed that Arabic-speaking learners of English demonstrated poor knowledge of collocations on the four tests. The study concludes with pedagogical implications, limitations, and suggestions and recommendations for future research.
\end{abstract}

\section{General Introduction}

Scholars have reiterated the fact that lexicon study is of great importance to and a central part of language learning. Some scholars have even stressed that, no matter how skilled students are at grammar, communication will cease without the words to convey meaning (McCarthy 1990). Milton (2009:3) comments that vocabulary is not an elective or insignificant component in the language acquisition process insomuch as "words are the building blocks of language and without them there is no language."

Throughout history, vocabulary learning has been sidelined in teaching of second languages and learning pedagogy, as will be presented in more detail in part 1. O'Dell (1997, cited in Milton 2009) states that, throughout the 1970s and 1980s, vocabulary and lexis are absent from main books on the syllabus and theory of language teaching. This apparent neglect of vocabulary teaching was largely due to the linguists' great emphasis on syntax and phonology over vocabulary, under the assumption that vocabulary acquisition could take care of itself (Decarrico 2001). Nonetheless, by the late 1970s and early 1980s, many voices started to defy the view that vocabulary can be absorbed naturally. This has resulted in the revival of interest in vocabulary teaching and the recognition of the significant role of vocabulary during language acquisition (Decarrico 2001).

However, the resurgence of interest in vocabulary would be fruitless without a clear understanding of the concept of knowing what a word means, an issue that is further explained in part 1. Based on this argument, Nation (2001) introduced a common aspect of word knowledge, receptive knowledge and productive knowledge. Another common aspect was presented by Anderson and Freebody (1981) which classifies word knowledge into breadth of knowledge and depth of knowledge. Nevertheless, the complexity of knowing a word cannot be solved by simple binary classification. Thus, Nation (2001) introduced a complete description of the range of word knowledge. He classified word knowledge into form, meaning, and use. Unfortunately, some of 
these types received great attention in teaching contexts such as word form and word meaning while other important aspects such as collocation (or use) are rarely mentioned (Hodne 2009).

Within the field of vocabulary, researchers have emphasized the importance of word combinations, also known as formulaic language. Conklin and Schmitt (2007) indicate that lexical combinations are very common in language discourse and differentiate the speech of native and non-native speakers. Erman and Warren (2000), for instance, analyzed native speakers' written and spoken discourses and determined that formulaic expressions represent 58.6\% of the spoken English discourse and 52.3\% of the written discourse. Foster (2001), who was looking for formulaic language in informal natives' speech, found that $32.3 \%$ of speech consists of formulaic expressions. Furthermore, Howarth (1998), when looking at 238,000 words of academic writing, claims that $31-40 \%$ was composed of collocations and idioms. Thus, all these studies show that formulaic language forms a large part of any discourse (Conklin \& Schmitt 2007). Knowing these formulaic sequences can facilitate the process of language learning.

As a subcategory of formulaic language, the notion of collocation has received considerable attention in the field of second language learning during the last few decades (Gitsaki 1999 \& Webb \& Kagimoto 2009). The term collocation "has its origin in the Latin verb" collocare which means "to set in order/to arrange" (Martyńska 2004:2). However, Firth (1957) is considered to be the first to explicitly introduce the term collocation (Gitsaki 1999; Lien 2003). In defining collocation, Firth argues that: "You shall know a word by the company it keeps." He exemplifies this by using the English words dark night as an example of collocation. He clarifies that one of the meanings of the word night allows its collocability with dark and vice versa (Hsu 2002, Zughoul \& Abdul-Fattah 2003). Subsequent researchers, who have studied the occurrence of collocation, dealt with its definition in various ways, as will be discussed in detail in part 1. Yet, there is still no precise noncontroversial, fixed definition of a collocation (Fontenelle 1994).

Learning collocations is regarded as an important and crucial part in L2 acquisition because the meaning of a lexical item has much to do with other lexical items that are combined with it. "Not only do these associations assist the learner in committing these words to memory, they also aid in defining the semantic area of a word" (Nattinger 1988). Ellis (2001, cited in Nation 2001) also takes a strong position on the importance of collocational knowledge by stating that it is the essence of language learning. Along the same lines, McCarthy (1990:12) argues that collocation is "an important organizing principle in the vocabulary of any language." Additionally, the significance of collocation can be clearly seen and perceived when observing the speech and writing of foreign learners who often fail to produce collocations in the proper order. This shows how important the knowledge of collocations is and calls for perception and concern by both L2 instructors and students (Carter \& MacCarthy 1988). Due to this importance, general-purpose learners' dictionaries (which include a fair number of collocations), monolingual dictionaries of collocation and bilingual dictionaries of collocation have been compiled for the sake of helping foreign language learners dealing with the difficulties they encounter "in vocabulary learning in general and collocations in particular" (Al-Zahrani 1998:26) (more about the importance of collocation to come).

Throughout the literature review, the phenomenon of collocation has been examined from different theoretical perspectives. However, three main approaches were the center of many studies that dealt with the concept of collocation or word combination, that is the lexical approach, the semantic approach and the structural approach. These approaches were an attempt by linguists (e.g., McIntosh 1961; Halliday 1966; Sinclair 1966; Fodor 1963; Cruse 1986; Mitchell 1971; Greenbaum 1970) to answer the question of whether collocation should be examined lexically, semantically or syntactically (more detail below).

Moreover, collocation has been classified in various ways. One classification views word combinations as a continuum of automaticity. At one end of the collocational continuum are free combinations whereas at the other end are idioms such as kick the bucket (Hsu 2002). On the other hand, a broadly adopted classification of collocation among researchers is the one proposed by Benson and Ilson (1986) in which they arranged English collocation into two major classes, lexical collocation and grammatical collocation. These classifications are discussed in greater detail in part 1 . The current study has adopted Benson and Ilson's model of collocation classification. The researcher attempts to investigate the advanced female/male learners' collocation competence by using both lexical collocations (verb-noun and adjective-noun) and grammatical collocations (verbpreposition).

In the field of first and second language acquisition, there have been many studies, as will be seen in part 1, that have acknowledged the existence and the influence of collocation in language acquisition (Fillmore 1979; Peters 1983; Ellis 1984c; Wray 2002). The majority of these studies support the view that language learners implement "a strategy of segmenting input speech into chunks on the basis of their repeated occurrence in certain situation, memorizing them, and recalling them for use as whole chunks when similar situations come up" (Zhang 1993:37). Most researchers in the field of first and second language acquisition highlight the fact that collocation plays an important role as scaffolding for creative construction of language (Al-Zahrani 1998). 
Experimental studies exploring female/male learners' knowledge of collocations are scarce despite the long-standing interest and increased attention of the last two decades (Channell 1981; Alkhatib 1984; Aghaar 1990; Hussein 1990; Biskup 1992; Farghal \& Obiedant 1995; Gitsaki 1996; Howarth 1998; Hsu 2002; ALAmro 2006; Shehata 2008) (more detail of these studies is in part 1). The main focus of these empirical studies included measuring collocational knowledge in general, examining the relationship between female/male learners' collocational knowledge and their overall language proficiency, development of collocational knowledge, pedagogical aspects on collocations, and types of collocational errors. Nevertheless, all of these studies indicated that male/female learners do encounter difficulties in collocating words, as manifested by their performance (Al-Zahrani 1998). Many researchers have attributed this lack of knowledge of collocation among learners to the neglect of instruction in classrooms (Li 2005). Others (Howarth 1996; Brown 1974) explained that some language teachers are unaware of the concept of collocation; thus they cannot direct students' attention to it when it is introduced in teaching materials.

Since most of the empirical studies on collocations were based on unsystematic collocation testing, with no consideration to detailed item analysis or test reliability and validity, the need for a reliable and valid instrument is of great importance to understanding the concept of collocation. Thus, Bonk's (2000) productive grammatical collocations (verb-preposition) test with few changes has been adopted. According to Bonk, the instrument was carefully developed and has undergone thorough statistical procedures to confirm its validity. For the lexical collocations (verb-noun and adjective-noun) test as well as the receptive test, I have adopted Shehata's (2007) instrument with minor modifications. The instrument also went through some procedures to eliminate some issues that might affect its validity. The design of these instruments is discussed in detail in part 2 .

The current study differs from previous studies in several ways: (a) It evaluates the productive and receptive knowledge of collocations among participants in two different gender settings: an male setting (advanced female English learners at Taif University, Saudi Arabia) and the setting (Advanced male English learners in the Department of Foreign Languages at Taif University); (b) It examines the participants' performance on two different tests (fill-in-the-blank and judgment-appropriateness tests) of three categories of collocations (verb-noun, adjective-noun, and verb-preposition collocations). To the best of my knowledge, only one study has examined the collocational knowledge of Arabic-speaking learners of English in an ESL setting. The intent of this current study is to be a useful addition to prior research in general, and to the limited studies of collocations with Saudi language speakers in particular.

\subsection{Research questions}

1. Is there a significant difference in the collocational competence of Arabic-speaking advanced learners of English in ESL environments when compared to those studying in male environments?

2. Is there a significant difference between the participants' productive and receptive knowledge of collocations?

3. Is there a significant difference between the participants' performance on the verb-noun, adjective-noun, and verb-preposition collocation tests?

\subsection{Research hypotheses}

$\square$ Female participants have more advanced collocation competence than male participants.

Participants performance on the receptive test will be higher than on the productive test.

Participants will do better on the verbnoun collocations test than on the adjective-noun and the verbpreposition collocations tests.

\section{Literature Review}

This section begins with a historical overview of the status that vocabulary has occupied up until the present day, followed by a discussion of the issue of what it means to know a word. The next section introduces the core subject, collocations. In particular, it starts by reviewing the studies that define the notion of collocation from the perspectives of the lexical composition trend, the semantic trend and the structural trend, as well as the current various definitions of collocations proposed by linguistic studies. This is followed by a distinction between collocations, idioms and word combinations. The topics covered also include the common classification of collocations, the importance of collocations, and collocations in the field of first and second language acquisition. Finally, the Part concludes with a review of selected empirical studies on the collocational knowledge of female/male learners.

\subsection{History of vocabulary in language learning}

Up to the present day, vocabulary has been undervalued throughout its different stages, despite its crucial importance to language learners (Zimmerman 1997). Unlike issues such as grammatical competence, contrastive analysis, reading, or writing, which received great attention and interest from scholars and teachers, 
the teaching and learning of vocabulary was overlooked in research and methodology (Richards 1976). This evident neglect could be attributed to the idea that second language (L2) vocabulary acquisition would take care of itself or be absorbed naturally like the native language (L1) vocabulary (Schmitt 2000). Besides, linguists at that time prioritized syntax and phonology as "more central to linguistics theory and more critical to language pedagogy" (Zimmerman 1997:5). Such a restricted view of vocabulary has resulted in a lexical deficiency for learners and, hence, inability to construct natural speech and writing (Zughoul \& Abdul-Fattah 2003). To provide a better understanding of historical trends in vocabulary instruction, the following paragraphs will shed some light on the teaching approaches that were dominant in the nineteenth and twentieth century.

The Grammar Translation Method was the main language-teaching methodology at the beginning of the nineteenth century. It placed a heavy emphasis on explicit grammar and accuracy as the method became controlled in nature, while little attention was given to vocabulary. Reading and translating literary materials was the focus of the content (Zimmerman 1997). Vocabulary choice was based solely on the reading texts, and the necessary vocabulary was provided to students in the form of bilingual word lists (Schmitt 2000).

Because the Grammar Translation Method's focus on analyzing the target language (rather than gaining the ability to use it) was seen as a shortcoming, the Direct Method emerged by the end of the nineteenth century. This method emphasized oral exposure to the target language with listening as the main skill, then speaking. It was thought that through interaction during the classes, students would acquire vocabulary naturally. Simple and familiar everyday vocabulary and sentences were taught either through demonstration or by association of ideas (Zimmerman 1997).

Vocabulary was seen, for the first time, as one of the most important aspects of second-language learning when the Reading Method emerged. In this method, emphasis was placed on developing criteria for selecting vocabulary content. The Reading Method aimed primarily at facilitating reading skills by improving vocabulary knowledge. Intensive oral drills were seen as a means of reinforcing the learning of a target language, rather than analyzing it. This method later came to be known as Audiolingualism (Schmitt 2000).

In 1972, Hymes introduced the concept of communicative competence which underscored the sociolinguistic and pragmatic aspects. This helped to shift the focus from language 'accuracy' into 'appropriateness.' In other words, the emphasis on using the language for meaningful communication rather than grammatical accuracy gave birth to the Communicative Language Teaching approach (CLT). Though it was a meaning-based approach, vocabulary was given a "secondary status" that served as a support for issues of "functional language," such as how to make a request. Similar to the previous approaches, few instructions were given about how to handle vocabulary in CLT under the assumption that L2 vocabulary would take care of itself, like L1 vocabulary (Schmitt 2000).

Similar to the Communicative Language Teaching and other communicative approaches being developed, the Natural Approach appeared in 1977. It placed an emphasis on exposure, or comprehensible input, without reference to grammatical analysis, or resorting to the native language (Richards \& Rodgers 2001). Since vocabulary is the source of meaning, it was deemed by the approach to be central to the language learning process (Zimmerman 1997).

The aforementioned language teaching methodologies have shown that teaching practices have moved between "language analysis" and "language use." Similarly, vocabulary has had varied positions. Yet, most approaches did not know how to deal with vocabulary and their reliance was on either word lists or the assumption that vocabulary would be acquired naturally (Schmitt 2000).

Over time, language instruction has improved as linguists have started to recognize the complexity of the language learning processes. Techniques have been developed, as teachers and practitioners have obtained knowledge of what would expedite language acquisition. However, the most remarkable and significant change at the end of the twentieth century was the shift of focus from grammar, as the central role of language teaching, to vocabulary (Ma 2009). This change was summarized by David Wilkins (1972:111) as follows: "Without grammar very little can be conveyed; without vocabulary nothing can be conveyed."

In the last two decades, vocabulary has become an essential aspect of language learning and its importance has been imposed on all parties (learners, teachers, language specialists, and program designers). Similarly, language specialists have emphasized the need for curriculum designers, teachers and learners to create a systematic and principled approach to vocabulary. This increased interest in vocabulary has produced an expanding body of experimental studies, pedagogical materials and computer-aided research, most of which addresses questions of crucial importance for both teachers and learners, such as, what does it mean to know a word? (Decarrico 2001).

\subsection{Knowing a word}

Words are not isolated components of any given language, but are parts of many joint systems and levels. Consequently, there are many aspects and degrees of word knowledge required for learners to be able to 
use words properly and effectively (Nation 2001). Therefore, we must be explicit about what is meant by knowing.

A common principle is the classification of word knowledge into receptive or passive knowledge and productive or active knowledge. Receptive knowledge refers to words that can be identified when heard or read (listening and reading skills), whereas, productive knowledge is the ability to use and have access to words in speech and writing (speaking and writing skills). Since it is, to a certain degree, a useful convention, some educational institutions and material designers have adapted this aspect of word knowledge into word lists that are divided into words that can be learned passively and words that can be learned actively. Nonetheless, this division of words as passive and active may not be clearly or sharply defined in the mind "since good passive skills often require the reader or listener to actively anticipate the words that will occur" (Milton 2009:13).

Anderson and Freebody (1981, cited in Milton 2009) proposed another convention that vocabulary learning researchers find helpful. This is the differentiation between breadth of knowledge and depth of knowledge. Breadth of knowledge is defined as the number of words a person knows, while depth of knowledge refers to a learner's knowledge of various aspects of a given word. The concept of depth of vocabulary knowledge may refer to the links between words, and it involves knowledge of word association, collocation, or colligation.

The complexity of word knowledge cannot be really understood by simple two-fold divisions such as receptive and productive, or breadth and depth. A more complete and balanced framework of word knowledge is proposed by Nation (2001). Nation classifies word knowledge into three main categories: knowledge of form, knowledge of meaning, and knowledge of use. Each category, with both productive and receptive aspects, is further subdivided. Knowledge of form involves the spoken and written forms as well as word parts. Knowledge of meaning is divided into form and meaning, concepts and referents, and associations. Knowledge of use includes grammatical functions, collocations, and constraints on use.

The aforementioned aspects of word knowledge are of great importance to foreign language acquisition and pedagogy. Unfortunately, some of these facets of knowledge, such as form and meaning, are given more value in the classroom, while other contextualized aspects, such as collocation, are rarely mentioned (Hodne 2009).

The study reported in this thesis attempts to investigate an important aspect of word knowledge: collocation. In particular, the study examines the participants' productive and receptive knowledge of collocation in female/male contexts.

\subsection{Collocation}

I have stated previously that vocabulary knowledge is the most essential element in learning a foreign/second language. However, vocabulary knowledge requires more than just knowing a set of isolated words or knowing their basic meaning. Within the realm of lexis, the area of collocation is of prime importance to second language learning in general and word knowledge in particular. Kim (2009:1) comments, "Truly knowing a word means not only knowing the meaning of the word but also knowing the words with which it frequently co-occurs."

The term collocation has been generally used to refer to a phenomenon in which certain words have the tendency to co-occur regularly within a language. Hence, the word lean can exclusively collocate with meat, while the word heavy has rain, meal, traffic, and smoker as possible collocates (Bahumaid 2006).

Since the 1950s, a number of studies have attempted to describe and investigate the English collocation phenomena. These studies (e.g., McIntosh 1961; Halliday 1966; Sinclair 1966; Fodor 1963; Cruse 1986; Mitchell 1971; Greenbaum 1970) have focused on three distinctive trends: the lexical composition trend, the semantic trend, and the structural pattern trend. The lexical composition trend views collocation as a means of describing word meanings at different levels. The semantic trend relies on semantic features to predict lexical item collocates. The structural pattern trend uses grammatical patterns to examine collocations (Gitsaki 1999). The three trends are discussed in more detail in the following sections.

\subsection{The lexical composition trend}

The lexical composition trend is centered on the notion that words obtain their meanings from the words with which they co-occur. Firth (1957:192) is known as both the father of this trend, and was the first scholar to introduce the term „,collocation' into lexical studies. He looks at collocation as a component separated from grammar. Collocation, according to Firth, is a "mode of meaning." He maintains that the lexical meaning should be analyzed on four levels: the orthographic level, the phonological level, the grammatical level, and the collocational level. The word peer is used by Firth as an example to illustrate this; at the orthographic level, its meaning is distinguished from the group of pier. Next, at the phonological level, the pronunciation of peer is stated; then, at the grammatical level, the word peer can be used either as a noun or a verb, thus adding a further 
component of meaning. Finally, at the collocational level, another meaning of the word peer can be obtained when it collocates with the word group, (as in peer group) (Gitsaki 1999).

Furthermore, Firth's theory of lexical meaning views word associations as paradigmatic and syntagmatic relations of lexical units. These lexical units are depicted by two axes: a horizontal (syntagmatic) and a vertical (paradigmatic) one. The paradigmatic axis consists of lexical items that belong to the same class and can be replaced with one another in a particular context. The syntagmatic axis refers to the words' ability to collocate with one another. For instance, water in Tom drank some water stands in paradigmatic relation with juice, beer, or wine and in a syntagmatic relation with the words Tom and drank. The novelty of Firth's theory comes from the fact that he looked at the meanings of lexical relations from the syntagmatic relations, rather than from the paradigmatic relations, e.g., synonyms and antonyms (Gitsaki 1999).

Subsequently, Firth's concept of lexical meaning has been adopted and developed by his followers, known as the Neo-Firthians; the most prominent of these are McIntosh (1961), Halliday (1966), and Sinclair (1966). McIntosh (1961) viewed collocational patterns as independent of grammatical considerations, and as equally important as grammatical patterns. He took Firth's theory into further discussion and added the novel notion of range (which refers to the particular lexical items that frequently co-occur with other collocates) and range-extension (for example, when a word is combined to another partner). For example, putrid and rancid: though they are synonyms, they have various ranges; putrid collocates with fish while rancid collocates with butter (Lien 2003). Additionally, some lexical items have range-extension tendencies. To provide an instance for that, McIntosh (1961:336) explained that some people use the word smashing in a strange way as in, we had a smashing time yesterday evening. He comments:

"This implies that we are aware of having begun to hear the word smashing in environments (situational as well as linguistic) which hitherto we should certainly have considered inappropriate not only because of their being out of our previous experience but also because of being beyond what our range-sense would regard as even marginally tolerable."

Halliday (1966, cited in Al-Zahrani 1998) regarded lexical patterns as a complementary component to grammatical theory. He introduced the notion of set as another dimension to the collocability of words, one which he differentiated from collocations. A collocation, to Halliday, is a linear co-occurrence relationship among lexical units which collocate interchangeably, while the set is "the grounding of members with like privilege of co-occurrence in collocation" (1966:153). For example, the words bright, hot, shine, light, and come out are all members of the same lexical set, as they are frequent collocates of the word sun. Additionally, Halliday (1966) argued that the criterion for a lexical unit to be a member of a certain lexical set is its syntagmatic relation to a particular lexical unit rather than its paradigmatic relation to that lexical unit. For instance, the words strong and powerful belong to the same lexical set since they collocate with the lexical item argument. However, when there are collocates such as, car and tea, the lexical items strong and powerful will enter different lexical sets, for example, strong tea and powerful car. Halliday was also concerned with the collocational patterns that the lexical items belong to. For example, a strong argument has the same collocational patterns as the strength of his argument and he argued strongly. The reason is that strong, strength, and strongly are all parts of the same collocational pattern and therefore regarded as word-forms of the same lexical unit (Gitsaki 1999).

Like Halliday, Sinclair (1966, cited in Al-Zahrani 1998) also considered grammar and collocation as two different facets. He explained that in grammar, language structure is organized by a system of choices (for example, choosing between active and passive choices), whereas collocation deals with individual lexical units and their tendencies to co-occur. In other words, it is a matter of likeness of occurrence rather than a matter of choice. Sinclair defines collocation, in a wider sense, as any two words that occur together in an adjacent textual environment. Along the same lines, he wrote: "There are virtually no impossible collocations, but some are much more likely than others" (p. 411, cited in Hsu 2002:110). Later, he refined his definition of collocation by stating that words do not take place arbitrarily in a text. As a result, Sinclair introduced the open-choice and idioms principles for language organization. He maintained that "the open-choice principle does not provide for substantial enough restrains on consecutive choices." Sinclair also introduced a new set of linguistics terms such as node, span, and collocates as his major contribution to the study of collocations. He defined node as the lexical item being examined, while span refers to the lexical units on either side of the node, and collocates refers to those items within the span. For example, when we examine the collocational patterns of the word tea that means tea is the node. If we want to have a span of three, then we should examine the three words before and after tea. All the words that are within the span of tea are labeled as its collocates (Gitsaki 1999).

In sum, the advocates of the lexical composition trend consider collocations as a separated and independent entity from grammar. They propose that collocation patterns are best examined and analyzed through lexical analysis that is concentrated on the syntagmatic co-occurrence of lexical units. However, they do admit that assistance from grammar is still required. Many collocational studies, conducted by different researchers, indicate that lexical collocations pose difficulties to L2 learners (e.g., Newman 1988; Aghbar 1990; 
Bahns and Eldaw 1993; Al-Zahrani 1998). Thus, the present study has included lexical patterns of collocations in the investigation of female/male learners' receptive and productive knowledge of collocations.

\subsection{The semantic trend}

Scholarship on collocations as the focus of linguistic studies, can be traced back as early as $300 \mathrm{~B}$. C. Greek Stoic philosophers, as Robins (1967:21) maintained, had acknowledged collocations in the studies of lexical semantics. They opposed the notion of "one word, one meaning," and highlighted the significant aspect of the study of the semantic structure of language: "word meanings do not exist in isolation, and they may differ according to the collocation in which they are used."

In parallel to the lexical composition trend, the semantic trend explores collocations from the semantic point of view separately from the grammatical. The approach is an attempt to describe why words are combined with certain other words (Lehrer 1974). The supporters of the semantic trend described the Neo-Firthians' approach to the study of collocations as inadequate as it failed to justify the arbitrariness of collocability. In other words, the lexical composition trend categorizes lexical units into sets based on their collocations; however, there is no justification as to why some lexical words collocate only with certain other lexical words (Lehrer 1974). For instance, it is correct to say blond hair but not blond car.

The semanticists regard the semantic properties of the lexical word as the key or basis for deciding what words are combined with other words. For example, rancid collocates with butter, lard, oil, and salad dressing since they all have the same semantic feature of "oily" in common (Decrarrico 2001).

Nevertheless, this interpretation of the semantic approach (the view that lexical items collocate due to their semantic properties) created criticism for the semanticists since there are a number of collocations that are arbitrarily restricted. For instance, there is nothing in the meaning of drinker to explain why it collocates with heavy but not with strong or powerful (Shehata 2008).

Within the semantic trend, Katz and Fodor (1963), just like the Neo-Firthians, introduced a semantic theory that is also different from, but complementary to, grammar. The theory provides organized and generalized facts about the knowledge of meaning. As mentioned by Katz and Fodor (1963:173), "semantics takes over the explanation of the speaker's ability to produce and understand new sentences at the point where grammar leaves off." They acknowledge that a dictionary is one component of a semantic theory of a natural language. Using an English dictionary as a model, they present the semantic markers of some lexical entries. Each entry of a word, based on the theory, has to meet with a condition, referred to by the authors as "selection restriction," to allow the collocation with other words. For example, one selectional restriction of the lexical item kill would require an object of the semantic feature [+Animate] (Kim 2009).

Nonetheless, one weakness of the semantic theory is that it does not explain arbitrary collocations. To deal with this limitation, Cruse (1986) presented "collocation restrictions." Three types of collocational restrictions (systematic, semi-systematic, and idiosyncratic) were described and distinguished based on whether, and to what extent, the semantic properties of a certain word predict a particular collocant. The lexical items grill and toast exemplify the systematic collocational restrictions. From the perspective of the agent, both verbs signify the same actions, yet, they are different from the patient viewpoint, as grill is used for raw items whereas toast is normally reserved for cooked items. Semi-systematic collocational restrictions refer to a lexical item's collocants that show certain semantic properties to predict a particular type of collocant, yet there are "exceptions to the general tendency" (Cruse 1989:281). For example, the word customer means that you receive something material in exchange for money, while client indicates that you obtain a technical service. Thus, bakers and newsagents have customers, but solicitors and advertising agencies, on the other hand, have clients. However, banks call the people using their services customers, not clients. Finally, idiosyncratic collocational restrictions denote the collocational ranges of some words that can only be described by listing their allowed collocants. For example, one can say flawless/immaculate performance but not unblemished or spotless performance (Cruse 1989). Despite Cruse's effort to provide an explanation for the collocational restrictions, there are a great number of idiosyncratic collocations that are arbitrarily restricted. Such arbitrarily restricted collocations have created problems to semanticists as many have been left marginal or unexplained (Gitsaki 1999).

To sum up, semanticists argue that the syntagmatic lexical relations should be examined under the area of semantics; nevertheless, they did not progress in the study of collocations, nor have they made the concept of collocation any more explicit (Gitsaki 1999).

\subsection{The structural trend}

The structural trend consists of studies that are centered on the belief that collocation is affected by structure and hence collocational knowledge should be examined by taking into account their syntactic features (Hsu 2002). Mitchell (1971:43), one of the advocates and the leading figure in this approach, criticized the NeoFirthians for their separation of lexical study from grammar. In his claim for the "one-ness of grammar, lexis 
and meaning," he contended that in order to determine the nature of collocation, linguists should consider grammar and lexis as one entity. Therefore, he proposed the notion of root to the study of collocations. According to Mitchell, the abstraction of a word form is called root, while word is the attachment of inflectional markings to the root. He claimed that collocations are of roots rather than of words and "are to be studied within grammatical matrices" (p. 65). For instance, Mitchell (1971) considered drink as the root of the word drinker and the conjunction of the roots heav- and drink in the example heavy drinker or drink heavily as collocations.

Nonetheless, Mitchell's argument that collocations are roots rather than made of words can't be generalized on every co-occurrence of roots. For instance, the collocation of the roots faint and praise is acceptable in she was damned by faint praise but not in he praised her faintly (Gitsaki 1999). Greenbaum (1970:11) also emphasized the influence of structural patterns on collocation, as some examples of collocations demand grammatical information. He maintained that "a serious disadvantage of a purely item-oriented approach to the study of collocations is that it obscures syntactic restrictions on collocations." To exemplify this, he used the word much, which collocates with the word like in a negative sentence (e.g., I don't like him much), but not in an affirmative sentence (e.g., I like him much). Greenbaum (1974) believes that without tying collocation to syntax, any two lexical items can collocate at a certain arbitrary distance. Thus, we can say: his sincerity frightens us, but not that we frighten his sincerity. This is because the acceptability of the collocation of the lexical items sincerity and frighten can only be determined by syntax.

Subsequently, the main achievement of the structural trend is the compiling of the BBI Combinatory Dictionary of English (Benson, Benson and Ilson 1986a), which is regarded as the first attempt to organize English collocations. The dictionary includes both lexical collocations (e.g., verb-noun, adjective-noun) and grammatical collocations (e.g., lexical item + preposition) (Gitsaki 1999).

Briefly, the structural trend underlines the significance of both lexis and grammar in the examination of collocations. Moreover, it pointed out that advocates of both the lexical and the semantic trends, examined a small set of lexical items due to their separation of grammar. Thus, their results were limited. Conversely, the structural researchers examined more patterns of collocations providing a well-developed, feasible, and systematic framework of the studies of collocations with a richer body of empirical studies. Hence, in this study, the author included both lexical and grammatical patterns of collocations to thoroughly study collocation and justify its nature.

\subsection{Recent views of the definition of collocation}

Since the introduction of Firth's concept of collocation, which explains meaning at the syntagmatic level, many researchers have encountered difficulties in providing a more rigorous way of defining collocation. Up until now, the definitions of collocation presented in various studies still lacked clarity and precision about the relation between lexical items' co-occurrence. Meanwhile, the criteria utilized by researchers, to determine collocations in a language, are various and manifest different views.

Among the many, varied perspectives and interests in defining the term "collocation," two major views can be identified. In one view, collocation is defined as the combination of lexical items at a certain distance that differentiate between frequent and non-frequent collocations. This view is referred to as the "statistically oriented approach" or "frequency-based approach" (e.g., Sinclair 1991; Stubbs 1995; Moon 1998). In the other view, collocation is considered as a kind of word combination that is fixed to a certain degree, but not entirely. This view is called the "significance-oriented approach" or the "phraseological approach" (e.g., Cowie 1993; Hausmann 1989). The advocates of the first view (frequency-based approach), are often concerned with the "computational analysis of syntagmatic relations" (Nesselhauf 2005:12). However, researchers of the second view, usually work in the areas of lexicography or pedagogy.

Additionally, collocation has been used in a vast array of definitions by scholars, whether it has been influenced by the two earlier-mentioned views or adopted a different approach. For instance, Benson, Benson, and Ilson (1986), who were influenced by corpus-based research, provided a general definition of collocations: "In English, as in other languages, there are many fixed, identifiable, non-idiomatic phrases and constructions. Such groups of words are called recurrent combinations, fixed combinations or collocations" (p. ix). Nattinger and DeCarrico (1992) declared that collocations are strings of particular words "that co-occur with a mutual expectancy greater than chance" (p. 36), such as rancid butter and curry favor, which are arbitrary collocations. They consider phrases such as for example and how do you do as collocations with pragmatic functions. Howarth (1998), on the other hand, viewed collocations as the co-occurrence of lexical items with a grammatical function as components of sentences (e.g., noun or prepositional phrases). Furthermore, Lewis (2000) defined collocation as naturally co-occurring lexical items in statistically important ways. Nation (2001:324) claimed that it is insufficient to define collocation as a group of lexical items that frequently cooccur. According to Nation, "collocations are closely structured groups whose parts frequently or uniquely occur together. We would also expect collocations to contain some element of grammatical or lexical unpredictability or inflexibility." 
However, in spite of the confusion and inconsistency in defining the notion of collocation, a general consensus exists among scholars of the main characteristics of collocations; that is, the strong tendency of two or more lexical items to co-occur in a particular context (Zhang 1993; Gitsaki 1999; Hsu 2002; Sung 2003).

Nevertheless, the above definition of collocations does not provide a reliable criterion of what constitutes a collocation. For instance, it most likely includes idioms as a part of collocations. Consequently, the issue of whether collocations should be separated from idioms has been argued among researchers. Thus, in an attempt to provide a clear picture on the definition of collocation that will be used in the current study, I believe it is necessary to shed more light on the distinction between collocations, idioms, and free word combinations.

\subsection{Collocations, idioms, and free word combinations}

If word combinations can form a continuum with idioms at one end and free word combinations at the other end, collocations are most likely to be placed in the middle (Gitsaki 1999; Hsu 2002). Idioms are described as relatively frozen expressions; they are fixed in structure, their meanings cannot be derived compositionally or retained from the meaning of their component words, and the lexical components cannot be substituted with synonyms (Bentivogli \& Pianta 2003). For example, one can say kick the bucket (to die) but not kick the pail or boot the bucket. Also, in the previous example, there is no actual bucket to kick. Free word combinations, on the other hand, are a combination of lexical items that abide by the general rules of syntax, and the lexical components are not bound to each other; they can be freely replaced with other words (Benson et al. 1986). The verb write, for instance, can freely collocate with a letter, a book, an essay, and so on.

As previously mentioned, collocations appear somewhere in the middle between the two boundaries because they "combine together the syntagmatic restrictions of idioms and the semantic transparency of free combinations" (Hsu 2002:18). Collocations are a sequence of lexical items that habitually combine with one another and whose meanings can be built compositionally. They usually allow a limited degree of substitution of their lexical components (e.g., do your best and try your best but not perform your best) (Bentivogli \& Pianta 2003). The view of placing collocations in the middle part of the scale has been largely accepted by many scholars of lexical units (Nattinger and DeCarrio 1992; Howarth 1996; Gitsaki 1999; Lewis 2000). Nattinger and DeCarrio (1992), for instance, view the development of collocations akin to a lifecycle: a collocation starts as a free combination and once it is used habitually, it becomes more fixed until it is called an idiom.

Supporting the same point of view and presenting a clear illustration for the continuum of word combinations, Cowie and Howarth (1995, sited in Schmitt 2000) propose a four-level scale of collocational complexity (see Table 2.2). At level one, idioms (e.g., bite the dust or shoot the breeze) are considered as frozen collocations allowing no variation or insertion of words, and hence, are the least complex. As the scale moves down, variation and complexity increase. For example, invariable collocations such as break a journey or from head to foot are at level two while collocations with limited choice at one point (e.g., give/allow/permit access to) and collocations with limited choice at two point (e.g., dark/black as night/coal/ink) are at level three and four respectively. Overall, many researchers have pointed out that it is not a simple matter to differentiate between idioms and collocations as they overlap with each other. in spite of this, they agreed that separating idioms from collocations produce less useful results (Hsu 2002).

As stated earlier, there is a wide variety in the criteria utilized by researchers to define collocations. However, before proceeding to the operational definition of collocations that will be restricted to the current study, it is necessary to make reference to the most common classification of collocations. The simplest and most adapted classification of collocations among researchers is the categorization of collocations into two major groups: lexical collocations and grammatical collocations. Lexical collocations consist of merely content words such as nouns, verbs, adjectives, and adverbs with an inclusion of prepositions, infinitives, or clauses (Table 2.3). Grammatical collocations, on the other hand, comprise of the main word: a noun, an adjective, or a verb plus a preposition (e.g., reason for, pick on, afraid of, so on) (Benson et al. 1986). The present study focuses on both lexical and grammatical collocations; particularly on verb-noun, adjective-noun (lexical collocations), and verb-preposition (grammatical collocations).

Table 1: Lexical collocations types

$\begin{array}{ll}\text { types of Lexical Collocations } & \text { Examples } \\ \text { Verb + noun } & \text { compose music/dispel fear } \\ \text { Adjective + noun } & \text { reckless abandon/warmest regards } \\ \text { Verb + adverb } & \text { appreciate sincerely/affect deeply } \\ \text { Noun + verb } & \text { alarms go off/blood circulates } \\ \text { Noun + noun } & \text { a herd of buffalo/an act of violence } \\ \text { Adverb + adjective } & \text { strictly accurate/keenly aware }\end{array}$

In sum, considering the previous current views on the definition of collocations, the distinction between collocations and idioms, as well as the classification of collocations into grammatical and lexical, the 
current study has adapted an operational definition of collocations. This definition includes the following features:

1. Collocations that consist of two or more words that more or less frequently co-occur (Zhang 1993).

2. Collocations that are a combination of two or more words that fall in the middle between idioms (e.g., spill the beans) and free word combinations (e.g., beautiful girl) which allow

a limited degree of substitution of their lexical components (e.g., do your best and try your best but not perform your best) (Bentivogli \& Pianta 2003).

3. Collocations that are less grammatically fixed, allowing changes in their word order or part of speech (e.g., inflict a wound, the wound was inflicted) (Nation 2001).

4. Collocations whose components are close or adjacent to each other (e.g., right-handed) (Killgariff 1992; cited in Hsu 2002).

5. Collocations that are semantically transparent and whose meanings can be comprehended based on the literal meanings of their components (e.g., spend money), unlike idioms (e.g., kick the bucket) (Gitsaki 1999; Nation 2001; Hsu 2002).

6. Collocations that are less lexically fixed, allowing substitution in at least one of their constituent components (e.g., take place/action, make difference/ mistake) (Al-Zahrani 1998; Gitsaki 1999; Hsu 2002).

7. Collocations that are not restricted just to pairs, but occur between words and phrases as well (e.g., take the necessary actions, talked him out of it) (Nattinger and DeCarrico,1992; Gitsaki 1999; Schmitt 2000).

\subsection{Collocation in first-and second-language acquisition}

The existence of collocations has been acknowledged by the majority of linguists in the field of firstand second-language acquisition. According to Bloom (1973, cited in Miyakoshi 2009), young children acquiring their first language produce unanalyzed chunks that an adult would recognize as multi-morphemic, such as lemme-see, i-wanna- do-it. This phenomenon questions the validity of the general assumption that most children start producing only one word at a time.

The importance of collocations in the process of first-language acquisition was highlighted by Wray (2002). He describes several essential roles of collocation in learning a first language. By using collocations, young children supplement gestures and other nonlinguistic behaviors when conveying salient messages prior to the development of their rule-governed language. Thus, children store and use complex strings before developing their grammatical knowledge. For example, a child may produce the string what's-that? before knowing the internal makeup of wh-questions. Another role that their use of collocations can play is to "reduce the child's processing load once novel construction is possible" (p. 128). This allows the child to maintain fluency while obtaining control of processing.

The significant role of collocations in the acquisition and use of a first language was also underlined by Peters (1983). In her study, Peters reveals that young children adopt both a gestalt (holistic) and an analytic (inferential) approach to acquiring a language. Children begin by extracting speech formulas from adults and then store and later reuse them creatively as both analyzed or segmented units and unanalyzed or whole chunks. In the field of second language acquisition, children seem to have many advantages over adults with regard to the acquisition of collocations. Leaving aside the biological factor, children interact with other children who are very lenient to incomprehension. They are also involved with various types of "ritualized play" that presents them with highly anticipated, constant, and contextualized language. Additionally, an adult, unlike a child, avoids the shock of being a nonspeaker of the new language by choosing not to communicate with other peers (Wray 2002). Such advantages facilitate the second language acquisition process in general, and assist children to sound native and idiomatic in their use of formulaic expressions in particular.

To maintain the above view, Fillmore (1979, cited in Al-Zahrani 1998), for example, examined the acquisition of formulaic speech of five Spanish-speaking learners of English paired with their counterparts (English-speaking children) for one year. The findings of her study reveal striking similarities in the use of formulaic sequences between the two groups. She explains that her subjects began by learning the formulaic expressions as unanalyzed or whole chunks, and later, after gaining confidence in their use, they start segmenting them into individual units. She comments:

"Once in the learner's speech repertory, they become familiar, and therefore could be compared with other utterances in the repertory as well as those produced by the speaker. Their function in language learning process, is not only social, but cognitive too, since they provide the data on which the children were to perform their analytical activities in figuring out the structure of the language."

Post-childhood second language acquisition, on the other hand, is viewed from a different perspective. According to Wray (2002), adult second language learners reveal themselves by not knowing the grammatically possible ways of conveying a message that sounds idiomatic for native speakers. The reason, he maintains, is that an adult language learner starts with individual units and then builds them up, whereas a first language 
learner begins with large and complex units and never segments them unless it is necessary. "Phrases and clauses may be what learners encounter in their input material, but what they notice and deal with are words and how they can be glued together" (p. 206). Consequently, a classroom learner aims for individual words and disregards what other words they may be combined with. For instance, when native speakers encounter the collocation major catastrophe it would be stored as a sequence without the need to analyze or segment its units. Thus, native speakers would know that the right way to express a big or terrible disaster is to say major catastrophe. In contrast, adult second-language learners would segment the string major catastrophe into two words meaning big and disaster and then store them individually, without realizing that this combination goes together. Therefore, when the time comes to talk about the same idea again, they will start looking for any pairing that conveys the same meaning as major (e.g., big, large, important) and catastrophe (e.g., disaster, calamity, mishap), which may or may not sound like native speech (Wray 2002).

Nevertheless, formulaic language still plays a crucial role in the field of second-language acquisition. Ellis (1984c, cited in Al-Zahrani 1998) indicates that wholes or chunks can form an entire script of L2 performance such as with the greeting sequences. In his study, Ellis points out that three ESL learners employed some sort of formula as a communication strategy (e.g., how do you do? I wanna, I can't speak English). He determined that formulas are common in both classroom and naturalistic settings and are utilized by L2 learners to decrease the learning burden, while increasing the communicative demands. Although collocations were not the focus of this study, but rather were included under the umbrella of formulas, this does not undervalue the importance of collocations.

In conclusion, findings in the area of both first-and second-language acquisition have underscored the role of collocations in language acquisition. While collocations are important building blocks in children's language acquisition, I believe collocations also play a significant role in adult second-language learning. The relevance of these findings to the current study lies in the need for developing female/male learners' collocational knowledge, which results from the process of learning and storing the collocations they encounter.

\subsection{The importance of collocation}

During the last two decades, the importance and value of collocations has been underscored by a number of linguists who identified the benefits of learning collocations, including improving language performance (Brown 1974; Nattinger 1980; 1988); the development of L2 vocabulary (Laufer 1988, Aghbar 1990); improving communicative competence (Yorio 1980; Channell 1981; Cowie 1988; Lewis 2000); and enhancing language fluency towards the level of a native speaker (Fillmore 1979; Howarth 1998; Nation 2001).

Brown (1974), who is one of the first advocates to emphasize the importance of collocations in L2 learning and their incorporation in the EFL/ESL classroom, points out that increasing students' knowledge of collocation helps improve oral proficiency, listening comprehension, and reading speed. Moreover, she argues that learning collocation enables learners to observe language chunks in the speech and writing of native speakers and consequently use these word combinations in their own speech. According to Brown, collocations, along with context and concept, should be incorporated when introducing new words to advanced learners because of their vital importance in language learning.

Nattinger (1980) claims that language production comprises "piercing together the ready-made units appropriate for particular situations and that comprehension relies on knowing which of these patterns to predict in these situations" (p. 341). Furthermore, Nattinger (1988) asserts that collocations are helpful in improving comprehension for the word combinations that aid learners in committing words to memory, as well as allowing learners to predict what kind of lexical items could occur together.

As to the development of L2 vocabulary, Laufer (1988) notes that the evident "rulelessness" of collocations is one issue that obstructs or hinders L2 vocabulary learning. She maintains that collocations represent a crucial aspect in the vocabulary knowledge of learners. Despite the fact that L2 learners encounter difficulties in the use of word combinations, collocations, as suggested by Laufer, can aid in many levels of vocabulary development. Collocations can also aid the development of self-learning strategies, such as guessing. For instance, when hearing the word intense, speakers are aware that it is combined with either pressure, heat, light, or feeling. They are also aware that the word convenient is not usually combined with people. Thus, a sentence like I'm not feeling convenient today is considered unacceptable. Such a guessing strategy can be developed through learning collocations.

Moreover, Aghbar (1990:5) points out in his study that the reason ESL learners perform poorly in the test of formulaic expressions is not due to a lack of vocabulary knowledge, but rather to insufficient learning of language chunks. Aghbar considers the role of overlearning as an important aspect in the acquisition and learning of formulaic expressions, in which he includes idioms, proverbs, sayings, and collocations. He notes that "although the construction of such chunks by and large follows the lexical and grammatical rules of English, we recognize them as formulaic only because we have a previous memory of them." 
The important role that collocations play in the development of male learners' communicative competence is underscored by Yorio (1980). Yorio claims that conventionalized language forms, including collocations, "make communication more orderly because they are regulatory in nature" (p.438). Along the same lines, Channell (1981) asserts that increasing learners' awareness and knowledge of collocations is a very effective way of heightening their communicative competence. Additionally, Cowie (1988) maintains that lexical phrases and collocations serve communicative needs and allow learners to reuse and produce the institutionalized units. And Lewis (2000) affirms that learning chunks or strings of words aid language learners in improving their communicative competencies better than merely learning words in isolation.

As far as enhancing language fluency is concerned, Fillmore (1979) considers fluency as a generic term that encompasses all characteristics of a speaker's competence and performance in a language. As maintained by Fillmore, one main constituent of fluency is the knowledge of fixed expressions of which collocations are part. Furthermore, Howarth (1998) suggests that collocations play an essential role in the learning of L2 and assist female/male students towards speaking more like native speakers. Similarly, Nation (2001) asserts that collocational knowledge is significant in enhancing fluency: "all fluent and appropriate language use requires collocational knowledge" (p. 318).

In light of the aforementioned studies, many researchers have studied the importance of collocations from different perspectives. Some (e.g., Brown 1974; Nattinger 1980; 1988) have addressed collocations in relation to the development of language performance in general. Others (e.g., Laufer 1988, Aghbar 1990; Yorio 1980; Channell 1981; Cowie 1988; Lewis 2000; Fillmore 1979; Howarth 1998; Nation 2001) have focused on particular benefits, such as the development of L2 vocabulary, improving communicative competence, and developing language fluency similar to native speakers. These factors all relate to the importance of collocations to second/foreign language learning and teaching. Thus, without the knowledge of collocations, female/male learners' expressions can be seen as unidiomatic, unnatural, or foreign, despite the fact that learners' speech would be grammatically correct. These unidiomatic interactions can cause misunderstandings, and, at worst, unkind smiles and other signs of disrespect.

A number of studies have reported the poor performance of second/foreign language learners on collocational tests (e.g., Channel 1981; Aghbar 1990; Biskup 1992; Bahns and Eldaw 1993, Zhang 1993). Moreover, learners' collocational errors occur more frequently than other errors (Ellis 2001). Accordingly, learners' difficulties in dealing with collocations are a crucial fact that has been affirmed by quite a number of studies in both female and male settings. The next section presents these studies in detail.

\subsection{Empirical studies on collocation}

Although both the importance of, and the need for, research on collocations have long been acknowledged, it is only in recent years that experimental research on female/male learners' collocational knowledge has been systematically conducted. Many of these studies have reported learners' insufficient knowledge of collocations, as well as the difficulties learners encounter in dealing with collocations on both the receptive and productive levels. As shown by learners' performance in second language studies, collocational errors constitute a large percentage of all errors made. However, among these studies, the main focuses included: measuring collocational knowledge in general; examining the relationship between female/male learners' collocational knowledge and their overall language proficiency; developmental patterns of collocational knowledge; and types of collocational errors. The following table (2.4) represents an overview of the some empirical studies that examined the previous aspects.

Table 2: Summary of empirical studies in terms of collocational knowledge

Source

Channell (1981)

Elkhatib (1984)

Aghbar (1990)

Hussein (1990)

\section{Participants \\ 8 EFL students}

4 undergraduate Egyptian ESL learners

27 faculty members teaching college-level English courses, 44 native undergraduates and 97 advanced ESL students

200 third- and fourth-year undergraduates majoring in English
Instrument

Collocational grid

Writing samples

Cloze test

Multiple choice test

Results
EFL learners have
insufficient knowledge of
collocations.
Unfamiliarity with
collocations is one of the
major lexical errors.
ESL students performed
poorly on the collocational
test, while the faculty
members produced the most
appropriate responses.
Participants level of
performance on the receptive
test was unsatisfactory.


Biskup (1992)

Farghal \& Obiedat (1995)

translation task

Gitsaki (1996)

Howarth (1998)

Hsu (2002)

Al-Amro (2006)

Shehata (2008)
28 German and 34 Polish speaking advanced learners of English students

275 Greek learners of ESL (junior high school students)

10 non-native graduate students

9 Taiwanese participants majoring in English (7) and Banking \& Finance (2)

51 Saudi advanced English students
57 Jordanian advanced EFL
Translation task from English into German and Polish respectively
Fill in the blank test and an Arabic-English

were adopted: synonyms, paraphrasing.

Cloze test, essay writing task, and a Greek/English translation test

Writing samples

Writing samples, the teacher's class notes, pre-test and post-test, and videotapes

A cloze test, a multiple choice test, and an essay writing task
Polish students relied on accuracy rather than guessing.

German students used different strategies to surmise the meaning of the target collocations.

L1 transfer has a strong influence on the two groups' production of collocations.

Participants were deficient in producing acceptable collocations during the two tests.

Four strategies of lexical simplification

avoidance, transfer, and

A significant difference was found in the production of collocations between and within the three groups.

Grammatical collocations are easier to acquire than lexical collocations.

Verb-noun collocations (creation) were the most difficult for all subjects. The production of collocations in an overlapping cluster was the most common type of collocational error among participants.

Direct emphasis on lexical collocations helped students learn new collocations.

Slightly positive relationship between learners' use of lexical collocations and their overall language proficiency.

There was a lack of collocational knowledge among participants.

There is a relationship between EFL learners receptive and productive knowledge of collocations.

There is no significant correlation between the subjects' overall knowledge of collocations and actual usage.

35 ESL Arabic-speaking
learners of English and 62 learners of English and 62
Egyptian majoring in English a self-report questionnaire, two blank-filling tests, an appropriateness judgment test, and a vocabulary recognition test
Significant differences between the ESL and the EFL participants on both their productive and receptive collocational knowledge.

L1 interference had a strong effect on the participants' collocational knowledge. Participants did better in the verb-noun test than in the adjective-noun test.

Channell (1981) was among the earliest researchers to conduct a study on overall knowledge of collocations. In Channell's study, a group of eight male learners with advanced-level proficiency were asked to fill in a collocational grid. The grid consisted of four adjectives as its vertical axis and fifteen nouns as its horizontal axis. The findings reveal the learners' inability to produce a significant number of acceptable collocations: only $111(40 \%)$ out of 272 collocations were marked as acceptable. This is despite the learners' familiarity with the words included in the test. Moreover, Channell notes that "it is essential to present a good number of typical collocations at the moment a word is first acquired. This is particularly true for students who have little access to native speakers with whom they can 'try out' the collocational possibilities of new words 
they learn" (p. 120). At the end of her paper Channell maintains that a collocational grid, which can be a useful aid in strengthening vocabulary knowledge, is of vital importance to female/male learners.

Similar findings to Channell's study were drawn from Aghbar's study (1990). To test participants' command of collocations, Aghbar used a cloze test. The test consisted of fifty sentences in which a verb was missing in each sentence, and a noun was supplied. The study compared the performance of three groups (27 faculty members teaching college-level English courses, 44 native undergraduate students, and 97 advanced ESL learners at Indiana University of Pennsylvania) in accurately combining the target verb-noun pairs in formal contexts. The results showed that faculty members produced the most appropriate responses. The results also showed that ESL learners produced the lowest number of expected word combinations. As Aghbar points out, ESL learners performed well only on the items where the most frequent verb get was required. However, this is due to their tendency to overuse the verb get in contexts where other verbs are more appropriate (for instance, get independence rather than gain/achieve independence). He concluded that ESL learners' poor performance on the test was not due to their insufficient vocabulary acquisition but rather to the "lack of acquisition of those language chunks that make discourse fluent and idiomatic" (p. 6).

The development patterns of female/male learners' collocational knowledge have also attracted the attention of researchers. Gitsaki's study (1996) has contributed to the area of collocations, providing a different perspective and many valuable insights. In her study, Gitsaki claims that there seems to be a developmental process that L2 learners follow in the acquisition of collocations, which can be described and analyzed. She examined 275 Greek learners of ESL (junior high school students) at three different proficiency levels (postbeginner, intermediate, and post-intermediate), using three measurements: essay writing, a Greek-English translation test, and a cloze test. Thirty-seven collocation types, operationalized in the BBI Combinatory Dictionary of English, were adopted. The essay-witting task, in which participants were asked to write approximately 200 words on a given topic, was designed to elicit free production of collocations, whereas the translation task (consisting of 10 sentences in Greek for each of the three groups) and the cloze test were intended to measure the cued production of collocations. Gitsaki indicated that the target collocations used in both the translation and the cloze tests were chosen from students' textbooks and are nonequivalent to their mother tongue. The data yielded a number of interesting results with respect to the free production and cued production of collocations. In the essay writing test, Gitsaki reported that there is a significant difference in the production of collocations between and within the different proficiency groups, in relation to accuracy and the ample use of collocation types. The post-intermediate level is reported to be more accurate in the production of both grammatical and lexical collocations, as well as the use of various collocation types, than the other groups. Similarly, considerable differences are found across and within the three groups in the results of the translation and cloze tests, with the post-intermediate students being more accurate in their production of collocations. Additional findings, which are of importance to the current study, revealed that grammatical collocations, by and large, are easier to acquire than lexical collocations. Also, among the 37 types of collocations, verb-noun (creation) lexical collocations (e.g., draw conclusions, face problems) were the most difficult and highly challenging for all subjects in both the translation and the cloze tests. They were also infrequent in the subjects' writing samples. Gitsaki explains that this is due to the arbitrariness and unpredictability of such collocations that makes it difficult for L2 learners to cope with them. Finally, Gitsaki concluded that as language proficiency develops, collocational knowledge expands steadily. However, she argues that the acquisition of collocations is affected by factors such as familiarity, frequency of the input, and "salience" of the collocation types, that is simple grammatical collocations are acquired earlier, due to learners encountering and using them in everyday communication.

In recent research, a qualitative study was conducted by Hsu (2002). The study examines whether the teaching of lexical collocations would improve the development of Taiwanese EFL learners' collocational proficiency in a one-month, intensive, business English workshop. The data were collected from nine Taiwanese participants majoring in English (7) and banking and finance (2). The qualitative research methods used in the study include subjects' writings, the teacher's class notes, a pre-test and post-test, and videotaping of subjects' interviews, presentations, and classroom activities. The results show that direct emphasis on lexical collocations, in both spoken and written discourses, could help students learn new collocations. The data also showed a slightly positive relationship between learners' use of lexical collocations and their overall language proficiency. Moreover, Hsu supports Gitsaki's statement that there are some possible factors affecting students' ability to learn collocations. These factors include frequency of collocations, degree of idiomaticity, differences of L1/L2, teacher instruction, and language experience acquired outside the classroom. He concluded that it is necessary to include the teaching of collocations in the EFL classroom because it helps learners develop collocational competence.

Several studies of collocations have focused their attention on the collocational errors that L2 students may display. A number of researchers have conducted empirical studies to examine the types of collocational errors that are most common, or may occur frequently among learners. In order to know whether L1 has an 
impact on L2 learners' comprehension and production of collocations, Biskup (1992) conducted a comparative study, in which he examined 28 German- and 34 Polish-speaking advanced learners of English. Participants were asked to translate English lexical collocations (verb-noun) into German and Polish respectively. The results reveal that Polish students relied on accuracy in translating the target collocations rather than guessing. In other words, they translated only the target collocations they were sure of. On the other hand, the German group used different strategies to surmise the meaning of the target collocations, such as providing a definition or paraphrasing. The researcher explains that this result can be attributed to the influence of the educational systems in Poland and Germany. The Polish educational system insists on accuracy, while the German educational system emphasizes fluency and communication. With regards to L1 interference, the results show that L1 had a strong influence on the two groups' production of collocations. The errors made by Polish students were the result of either loan translations or extending L2 meanings on the basis of L1 words. On the other hand, the German students' production of errors resulted from negative L1 transfer; this includes in particular what Biskup refers to as "assumed formal similarity," such as code switches, false friends, blends, or hybrids.

In addition to L1 transfer, Howarth (1998) reported on a study which examined written academic performance in English. His data included the analysis of a set of 10 essays written by 10 non-native graduate students as coursework for an MA in applied linguistics in the University of Leeds in the United Kingdom. He pointed out that the majority of non-native speakers' (NNS) errors were the production of collocations in an "overlapping cluster," a cluster of collocations that could be "predicted by analogy, but are arbitrarily blocked by usage" (p. 37). For example, non-native speakers are more likely to say adopt a policy but not take a policy, make an attempt but not do an attempt. Furthermore, Howarth notes that although such collocational errors are recognizable to many EFL teachers, it still provides them with the hardest task in terms of description and explanation. The reason is that these kinds of combinations, which are different than the more restricted collocations and idioms, are not acquired whole. Howarth writes:

"While they are not fully lexicalized, they are quite institutionalized, and therefore form part of the stock of complexes that help to mark a piece of writing as natural and proficient. It appears that the ability to manipulate such clusters is a sign of true native speaker competence and is a useful indicator for the establishment of degrees of proficiency across the boundary between non-native and native competence." (p. 38)

To summarize, the abovementioned studies clearly show how essential collocations are in language learning as they have confirmed the poor and deficient knowledge of the collocations of female/male students in different levels of proficiency. Therefore, L2 teachers and curriculum designers should pay special attention to collocations in order to facilitate language learning and make it more enjoyable.

\subsection{Empirical studies of Arabic-speaking learners of English}

A careful review of the literature shows that the majority of collocation studies were conducted on Arab learners studying English in EFL settings (e.g., Hussein 1990; Farghal \& Obiedant 1995; Al-Zahrani 1998; Zughoul \& Abdul-Fattah 2003; Mahmoud 2005; Al-Amro 2006). To the best of my knowledge, Shehata (2008) conducted the only available study that has particularly examined Arab ESL learners' collocational knowledge. Another study that dealt with Arabic-speaking ESL learners was Elkatib's (1984); however, it examined general lexical problems, one of which was the error of "word collocations." Detailed discussion of some of these studies is presented below.

Elkhatib (1984) conducted one of the early studies that investigated the lexical errors of Arab ESL learners. Elkhatib analyzed the writing samples of four undergraduate Egyptian ESL students with the objective of classifying lexical problems, identifying the causes of the problems, and verifying whether learners were attuned to the substance or the form of the language. The analysis showed eight major lexical errors, including an unfamiliarity of collocations. Elkhatib observes that despite knowing the basic meaning of words, the subjects could not produce acceptable collocations. This lack of collocational knowledge caused the subjects to compose erroneous collocations such as shooting stones, the aircrafts can remove us to many countries, beautiful noise, and do progress. At the end of his study, Elkhatib suggests that in order to help overcome collocational problems, teachers should present new words along with their most typical collocations in the form of collocational grids (such as those utilized by Channell 1981) or of sample sentences.

In another study, Hussein (1990) employed a 40-item multiple-choice test for the aim of assessing and evaluating the subjects' receptive collocational knowledge. The sample consisted of 200 third- and fourth-year undergraduate students majoring in English at Yarmouk University in Jordan. Each item in the test included four choices. The majority of the collocations used in the test were verb-noun, adjective-noun, and noun-noun. The findings revealed the subjects' overall level of performance on the receptive test were unsatisfactory. Only $48.4 \%$ of the collocations were answered correctly, which was far below the initial set rate $(60 \%)$. Hussein maintains that the students' low achievement on the test can be traced to some general factors such as: negligence of the lexicon, including collocations, in the teaching of English as a foreign language, insufficient 
reading habits, and reduction and simplification, which seem to be characteristics of the teaching components of a foreign language. Other factors related directly to the test are: L1 negative transfer (e.g., death number in place of death toll), overgeneralization (i.e. the use of generic terms rather than specific, e.g., pipe water in place of tap water), and the unfamiliarity with idiom structure (e.g., primary voyage in place of maiden voyage).

In a later investigation, the issue of collocations as a neglected variable in EFL classroom was addressed by Farghal and Obiedant (1995). In their study, they examined the lexical collocational knowledge of 57 Jordanian advanced EFL learners. Two test instruments were used in the study: a fill-in-the-blank test and an Arabic-English translation task. A total of 22 common English collocations (adjective-noun collocations) related to topics such as clothes, weather, and food were used in both tests. The blank-filling test included 11 sentences testing collocation pairs; moreover, the translation task, which is an Arabic version of the blank-filling test, consisted of translating the given collocations from Arabic to English. The blank-filling test was administered to 34 English majors at Yarmouk University, and the translation task was administered to 23 English majors at the Higher College for the Certification of Teachers. The overall data analysis shows that both groups are unaware of the fundamental existence of collocations as multi-word units because they are taught vocabulary as singleword units. This teaching method resulted in both groups being unable to produce acceptable collocations on the two tests. In the absence of collocational knowledge, the subjects resorted to four different strategies of lexical simplification. These are as follows:

1. Synonyms: This particular strategy was used most frequently by the subjects. The author attributes the heavy use of this strategy to the subjects' lack of knowledge of the collocational restrictions of some lexical items as well as the direct application of the open choice principle. For example, the target collocation rich food was substituted with oily/greasy food.

2. Avoidance: By adopting this strategy, the subjects avoided using the target collocations in favor of other lexical items. Thus, they choose a related natural collocation that fails to reflect the intended meaning. For example, the elicited collocation soft/little food was substituted for the target collocation light food.

3. Transfer: This strategy yielded both positive and negative transfer. Positive transfer occurs when there is convergence between the Arabic language and the English language allowing the subjects to do well on predicting the target collocations (e.g., striped shirt). Negative transfer, on the other hand, occurs when there is divergence between the two languages in which the target collocations become unpredictable; for example, heavy tea instead of strong tea.

4. Paraphrasing: This strategy was the last resort that the subjects adopted (more apparent in the translation task group) in order to define the target collocations. The fact that the subjects used such a strategy indicates their deficiency in the acquisition of L2 collocations; for instance, does not change for the target collocation fast color.

Realizing the difficulties that male learners encounter when dealing with collocations, the authors propose some valuable implications: first, the open choice principle or word-for-word combinations should be presented early, alongside the pre-constructed multi-word combinations or the idiom principle in foreign language classrooms. Second, not only should the inclusion of collocations in the foreign language curricula be singled out, but pedagogic dictionaries of collocations should be compiled as well. Third, foreign language instructors should be qualified in teaching prefabricated speech in general and collocations in particular.

In a recent study, Al-Amro (2006) assessed the lexical and grammatical collocations of Saudi male learners as well as their productive and receptive collocational knowledge. The data was drawn from 51 Saudi advanced English learners at the Institute of Public Administration in Riyadh, Saudi Arabia. The subjects' collocational knowledge was measured by a C-test, a multiple choice test, and an essay writing task. The C-test consisted of 34 productive items (verb-noun and verb-preposition collocations) in which the initial letter of the target collocations is provided to reduce the possibility of guessing, whereas the multiple choice test included 16 receptive items (figurative-use of verb phrases) where the subjects had to select from four alternatives for the underlined verb that sounds strange or miscollocated. The collocation test is a modified version of Bonk's (2000) test that has a high level of reliability $(r=.83)$. The results showed that there was a lack of collocational knowledge among the subjects as manifested by their poor performance on the collocational test. The data also revealed that there is a relationship between the male learners' receptive and productive knowledge of collocations. However, the subjects performed better on the productive test $(\mathrm{M}=32.88)$ than on the receptive test $(\mathrm{M}=24.64)$, a finding that is paradoxical considering the evidence that receptive knowledge is typically much broader than productive knowledge. However, the author attributes this to the fact that the target collocations in the receptive test were of lower frequency than those in the productive test. The least expected 
result, reported by Al-Amro, was that there was no significant correlation between the subjects' overall knowledge of collocations and their actual collocational usage. In other words, the collocational knowledge from the collocational test did not correlate to the use of collocations in the essay writing task. Al-Amro concluded that the EFL learners' lack of collocational use is the direct result of the neglect of the lexical approach in the foreign language teaching and learning environment. When the teaching of collocations is overlooked learners focus mainly on single-word units while disregarding all the important associations of the word or its partners. Moreover, the overemphasis of using synonyms in dictionaries to find a particular meaning of a word has resulted in the misconception among learners that conceptual equivalence involves distributional equivalence.

In a more recent study, Shehata (2008) examined the L1 influence on the productive and receptive knowledge of collocations by advanced Arabic-speaking English students. The author recruited 97 participants who were divided into two groups, ESL and EFL. The participants in the ESL group included 35 Arabicspeaking English students at Ohio University who had TOEFL scores ranging from 567 to 620; whereas, the EFL group consisted of 62 Egyptian participants majoring in English at an Egyptian university whose English proficiency levels were advanced. The probe of the study consisted of five instruments: a self-report questionnaire, two fill-in-the-blank productive tests, an appropriateness judgment receptive test, and a vocabulary recognition test. Thirty-two target collocations were included in the productive collocation tests (16 each adjective-noun and verb-noun collocations). The receptive test consisted of 50 items that included the 32 target collocations in the productive tests plus 18 mismatched collocations that served as distracters. The participants' familiarity with collocational components was checked using the vocabulary recognition test which consisted of individual words. The findings yielded significant differences between female and male participants on both productive and receptive collocational knowledge. The author reported that female participants outstripped the male participants in both productive (female $M=20.71 / \mathrm{male} M=9.31$ ) and receptive (female $M$ $=38.80 / \mathrm{male} \mathrm{M}=36.24)$ tests. The results also showed that L1 interference had a strong effect on the participants' collocational knowledge. Another interesting finding was that all participants did better on the verb-noun collocation test than on the adjective-noun collocation. This indicates that verb-noun collocations are easier to acquire than adjective-noun collocations. Overall, Arabic-speaking male learners have poor knowledge of collocations. This can be attributed to the influence of the learning environment. To help improve male learners' collocational knowledge, the author calls for the use of authentic materials in teaching collocations, which in turns provides them with the opportunity to be exposed to natural language that can assist in the development of their language proficiency. Moreover, male teachers should pay more attention to the teaching of non-congruent collocations, that is collocations that do not have a translation equivalent in L1. She concluded that English textbooks should include a bilingual glossary of collocations to help learners to become more familiar with the similarities and differences between L1 and L2.

In conclusion, the previously mentioned studies have yielded evidence of the poor collocational knowledge of Arab EFL students and have shown that EFL classrooms need an approach that considers lexis and its components as important avenues in language learning. The last two aforementioned studies are highly relevant to the current study because it examined the productive and receptive collocational knowledge of L2 learners. It is in line with the studies that acknowledge the deficiency of ESL/EFL learners in the area of collocations. While the collocation studies that investigated Arabic-speaking learners of English are scarce, almost all of them were conducted in an EFL environment, and only one study has examined Arab learners of English in both ESL and EFL settings. Thus, the present study attempted to add to the existing research by exploring whether learning English in an ESL context has an impact on students' collocational knowledge in comparison with learning English in an EFL context. The design of the study follows that of Shehata (2008) and partly that of Al-Amro (2006) which will be discussed below in more detail.

\subsection{Conclusion}

In summary, this part provided a discussion of the status of vocabulary learning, word knowledge, and the core subject collocations. In particular, it explored the various definitions of collocations proposed by linguists and suggested a workable definition with the purpose of distinguishing collocations from other multiword units. Moreover, this section reviewed the acquisition of collocations in first- and second-languages as well as the significance of collocations in L2 learning and teaching. It concluded with an investigation of some empirical studies on the knowledge of collocations relevant to the current study.

\section{Research Methodology}

This section presents a description of the settings in which the study took place, the subjects who participated in the study, the probes used, the method, the data scoring procedures, and finally the research questions and hypotheses. 


\subsection{Setting}

The study was conducted in two different settings, female and male. The male setting was an English language center in a higher training institute in Saudi Arabia. The institute's major task is to train the Saudi youth to meet modern requirements in the job market. Upon entering the institute, students must successfully pass a one-year intensive English program in order to major in business administration, banking, office management, or similar subjects. Students in the English language center are required to attend four consecutive sessions: preparatory, elementary, intermediate, and advanced. Each session lasts for eight weeks, during which five courses are taught: reading, writing, speaking, listening, and grammar. The Computer-assisted Language Learning (CALL) program is also used. Classrooms are equipped with modern technology, such as overhead projectors and computers with Internet access. They have a capacity for thirty students.

\subsection{Participants}

Based on the participants' availability and research purpose, a total of 68 Arabic-speaking English students participated in this study. The participants in the male context included 38 Saudi female students at the intermediate level. However, their English proficiency level is believed to be equal to that of students at the advanced level. This is because when students reach the advanced level, they are assigned to different classes dependent on their majors. For example, if they are majoring in banking, they will be taking courses involving business terms rather than general English. In other words, intermediate-level students have advanced English proficiency, but are still required to take additional ESP classes. Additionally, the study was conducted on the seventh week of an eight week session. The participants' ages ranged from 21-35. Some of them had completed high school and some had earned a bachelor's degree.

Additionally, 30 male Arabic-speaking learners of English in the male campus. They either had just passed the intermediate level (level 300) or had just passed the program and were ready to take academic classes. The students were all at either undergraduate or graduate levels. All students in the English language center and the intensive English program were required to take a placement test prior to their admission. Approval to conduct the study on all participants was sought through the Taif University Vice Presidency for Higher Studies \& Academic Research (TUVPHSAR).

\subsection{The instruments}

The data-gathering portion of the study consisted of two parts: three gap-filling productive tests and an appropriateness of judgment receptive test. The three gap-filling tests were designed to measure the participants' productive collocational proficiency. They included 48 target collocations that examined three types of collocations: 16 verb-noun collocations, 16 adjective-noun collocations, and 16 verb-preposition collocations. The three tests were used in restrictive structures that allowed only one correct answer. In the verb-noun and adjective-noun collocations tests, the initial letters of the target collocations were provided as a clue, and in the verb-preposition test the meanings of the phrasal verbs were given. This was to prevent guessing and to ensure that participants selected only the target word (Appendix I).

The appropriate judgment test was designed to measure the participants' receptive competence in identifying the correct English collocations. It consisted of 75 items; the 48 target collocations used in the three gap-filling tests were included, along with 27 mismatched collocations that acted as distractions. The participants were asked to judge whether the underlined part of a sentence was acceptable or not by circling a number corresponding to the inappropriate part of the sentence (see Appendix II).

For the verb-noun and adjective-noun productive tests (as well as the receptive test) Shehata's (2007) instruments were adopted with minor modifications. The instruments went through some procedures to eliminate some issues that might affect their validity. One modification was the inclusion of the first letter of the target noun-verb and adjective-noun collocations. For the receptive test, the target collocations were underlined. For the verb-preposition productive test, Bonk's (2000) instrument was adopted. This instrument was carefully developed and demonstrated a high level of reliability $(\mathrm{r}=.83)$.

A pilot study was conducted on both non-native and native participants to check the validity of the instruments as well as to decide on the time needed for participants to finish each test. The target collocations that were missed by either all non-native speakers or by a native speaker were considered difficult and therefore were replaced with high-frequency ones. While participants taking the pilot tests were observed, it was noted that the receptive test created confusion in participants because they focused on parts of the sentences other than the target collocations. To solve this issue, the author decided to underline the target collocations and ask participants to judge only the underlined part of a given sentence.

\subsection{Method}

Upon approval of TUVPHSAR, the author contacted a faculty member at the English language center in Saudi Arabia and asked the faculty member to administer the two instruments on the author's behalf, due to 
the difficulty of showing up there. All details and procedures regarding the test administration were explained. The probe was conducted in two normal-environment classes that held 25 students each. The productive instrument was administered first and lasted for 25 minutes; the receptive instrument was administered right after the participants finished the productive test and lasted for 20minutes, according to the proctor. Both instruments were numbered, and each participant was given a number to ensure that the same participant took each of the two tests.

For the female students, the participants were approached individually because the author was unable to arrange the time and place for the participants. The same procedures were explained to each participant.

The participants in both settings were given 30 minutes to complete the productive test and 25 minutes to complete the receptive test. In order to preclude the possibility of guessing, participants were told not to use dictionaries and to leave blank any item they were unsure of.

\subsection{Data scoring procedures}

The set data of the four tests were scored as correct or incorrect because all items allowed for only one possible answer. The total score for each instrument was 48 for the productive test and 48 for the receptive test. Items unanswered were counted as incorrect. Morphological errors, such as the incorrect use of verb tenses (e.g., Governments should takes) and spelling errors (e.g., cought fire), were not considered. The mismatched collocations that acted as distracters in the receptive test were not counted.

\subsection{Research questions and hypotheses}

Research Questions:

1. Is there a significant difference in the collocational competence of Arabic-speaking advanced learners of English in ESL environments when compared to those studying in EFL environments?

2. Is there a significant difference between the participants' productive and receptive knowledge of collocations? 3. Is there a significant difference between the participants' performance on the verb-noun, adjective-noun, and verb-preposition collocation tests?

Research Hypotheses:

ESL participantshave more advanced collocation competence than EFL participants.

Participants performance on the receptive test will be higher than on the productive test.

Participants will do better on the verbnoun collocations test than on the adjective-noun and the verbpreposition collocations tests.

\subsection{Conclusion}

Having provided the research methodology as well as the questions and hypotheses in part 2, the study will proceed in the next section to a detailed examination of the results of the present study to test the abovementioned hypotheses, and whether they are proved or disproved. The results were statistically analyzed by means of descriptive statistics and inferential statistics using the Statistical Package for the Social Sciences (SPSS).

\section{Results Of The Study}

This section presents the findings of the study reported in part 2 and discusses them in relation to the thesis hypotheses. Descriptive statistics along with independent and paired samples t-test, one-way ANOVA, and post-hoc tests were used to calculate for the productive and receptive knowledge of collocations in female/male environment and to investigate the results of the four tests. Means and standard deviations were calculated and compared. Differences between all participants' scores in all test sections (productive verb-noun, productive adjective-noun, productive verb-preposition, and receptive) were examined and reported in order to address the thesis hypotheses.

\subsection{Collocational knowledge in the female and male settings}

To measure the mean differences between the two groups of participants on their collocational knowledge, descriptive statistics and two independent t-tests were performed. The alpha level was set at 0.05 before the test. Means and standard deviations are shown in Table 3. A cursory look at Table 4 reveals a statistically significant difference between the two groups in both their productive knowledge of collocations $(\mathrm{t}$ $=2.17, \mathrm{df}=66, \mathrm{p}<.005, \mathrm{sig} .2$-tailed $=.033)$ and their receptive knowledge of collocations $(\mathrm{t}=5.01, \mathrm{df}=66, \mathrm{p}$ $<.001$, sig. 2-tailed $=.000$ ). The descriptive statistics presented in Table 3 show that female participants performed significantly better than male participants. The female means on the productive and the receptive tests $(18.10,39.10$, respectively) were significantly higher than the male means $(14.47,31.81)$. 
Table 3: Mean Scores for female/male Productive and Receptive Collocation Size

Productive Test

Learning Environment

female $(\mathrm{n}=38)$

Mean

Receptive Test

male $(\mathrm{n}-30)$

14.47

Std. Deviation Mean

$5.87 \quad 39.10$

Std. Deviation

$7.86 \quad 31.81$

5.12

6.50

Table 4: Independent Samples T-test of female and male Productive and Receptive Scores

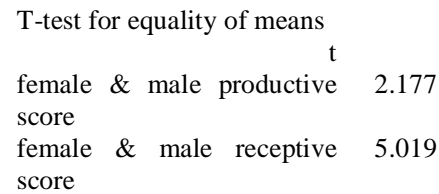

df

66

66
Sig. (2-tailed)

.000

\subsection{Productive and receptive collocational knowledge}

In order to investigate whether there is a significant difference between the participants' productive and receptive knowledge of collocations, a comparison was computed using a paired-sample t-test. For the resulting comparison, the alpha level was set at 0.05. Mean and standard defilation is shown in Table 3. As Table 4 indicates, the $\mathrm{t}$-test revealed that the difference between the mean score for both variables was significant $(\mathrm{t}=$ $22.41, \mathrm{df}=67, \mathrm{p}<.001)$. The mean score for the receptive test (35.02) was larger than that of the productive test (16.07), which demonstrated that participants' productive knowledge of collocations lagged behind and did not develop as their receptive collocational knowledge. This also supports the second hypothesis that participants' performance on the receptive test is higher than on the productive test. Standard deviations throughout indicate that the scores of both the productive test (7.00) and the receptive test (6.93) were relatively heterogeneous.

Table 5: Participants' Mean Scores on the Productive and Receptive Tests

$\begin{array}{llll}\text { Test Type } & \text { N } & \text { Mean } & \text { SD } \\ \text { Productive Collocations } & 68 & 16.07 & 7.00 \\ \text { Receptive Collocations } & 68 & 35.02 & 6.93\end{array}$

Table 6: Paired-sample T-test for the Productive and Receptive Total Scores

\begin{tabular}{|c|c|c|c|}
\hline \multicolumn{4}{|l|}{ Paired T-test } \\
\hline & t & $\mathrm{df}$ & Sig. (2-tailed) \\
\hline $\begin{array}{l}\text { Productive \& Receptive Total } \\
\text { Scores }\end{array}$ & 22.42 & 67 & 000 \\
\hline
\end{tabular}

Table 7: Correlations between productive and receptive knowledge of collocations Pearson Correlations Among Variables

\begin{tabular}{|l|l|l|}
\hline Productive score & Productive score & Receptive score \\
& 1 & $\begin{array}{l}.499^{* *} \\
.000\end{array}$ \\
\hline Receptive score & $.499^{* *}$ & 1 \\
\hline$* *$ Correlation is significant at the 0.01 level (2-tailed) &
\end{tabular}

\subsection{Collocation Types}

Descriptive statistics were calculated for the three types of collocation: verb-noun, adjective-noun, and verb-preposition (see Table 8). Percentage descriptive statistics are also presented in Table 8. Of the three types of collocation tested, none indicated an average score over $56.31 \%$ (for verb-noun), with adjective-noun and verb-preposition scores trailing far behind at approximately $21.18 \%$ and $22.93 \%$, respectively. The low standard deviations of the three types showed that the data were homogeneous and less spread out.

Table 8: Collocation Types’ Descriptive Statistics

Types of Collocations Range Minimum Maximum Total Possible Mean SD

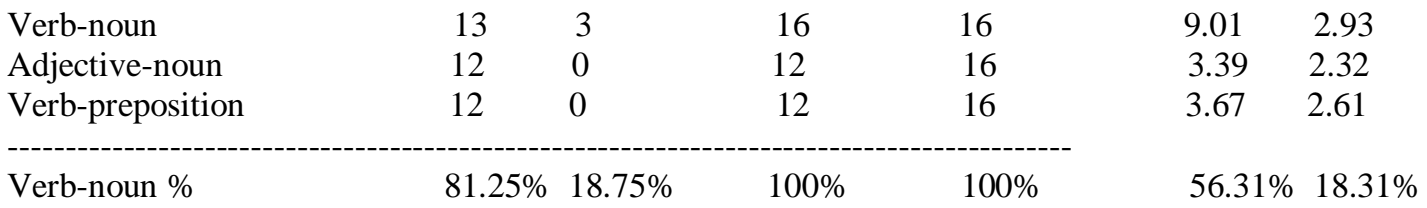




\begin{tabular}{|c|c|c|c|}
\hline n $\%$ & $75 \%$ & $0 \%$ & $75 \%$ \\
\hline Verb-preposition $\%$ & $75 \%$ & $0 \%$ & $75 \%$ \\
\hline
\end{tabular}

To investigate whether any difference existed between the participants' performances on the three types of collocation in the productive test, a one-way ANOVA (Table 8) was calculated in addition to post-hoc tests. The significance is decided by looking at the probability associated with each F-value (i.e., the effect is significant if $\mathrm{p}<.05)$. The ANOVA revealed a statistically significant difference between the three types of collocation, $\mathrm{F}=97.97, \mathrm{p}<.001$.

Table 9: One-way ANOVA of Performance on the Three Types of Collocation

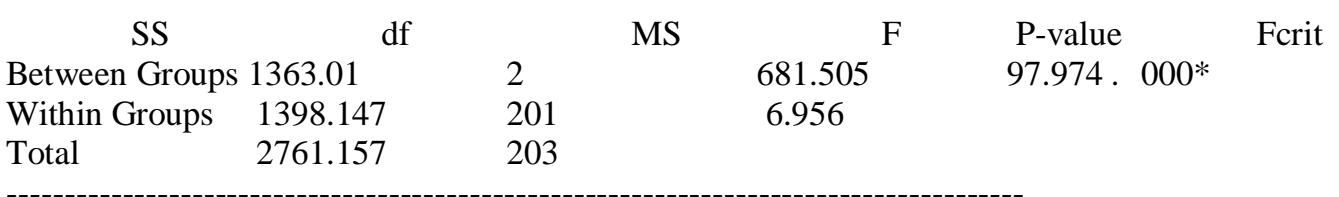

*The mean difference is significant at the .05 level

Tukey's HSD post-hoc tests (see Table 10) were also computed to determine where differences actually lay. The tests revealed that the differences between verb-noun collocation type and the other two collocation types were all statistically significant, whereas the difference between adjective-noun collocation type and verbpreposition collocation type was statistically non-significant.

Table 10: Tukey's HSD Multiple Comparisons of Performance on the Types of Collocation Comparisons of Component X and Component $\mathrm{Y}$ Mean Difference

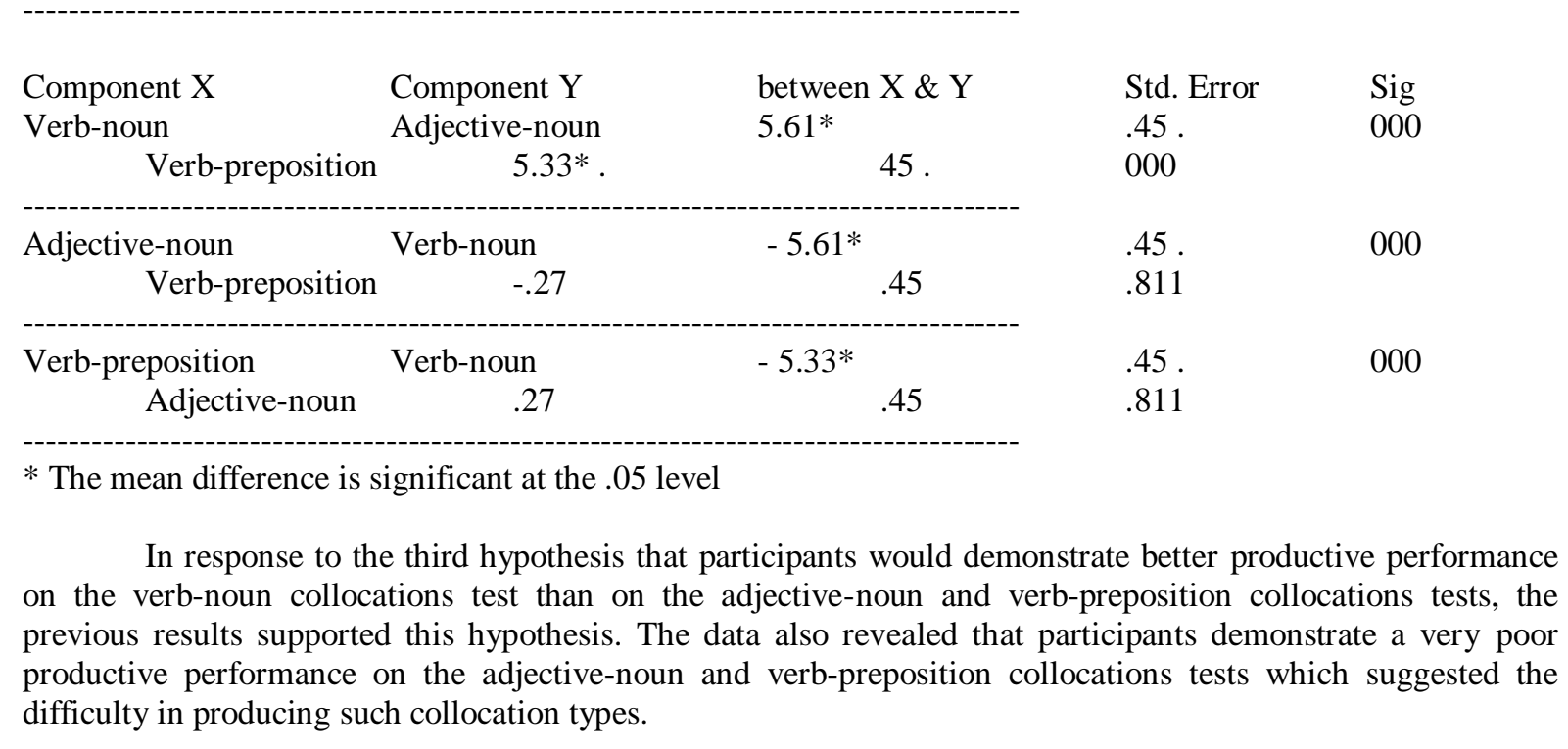

\subsection{Conclusion}

This part introduced the statistical procedures and the results of the study presented in part 2, as the author of the current study sought responses to the thesis hypotheses. Descriptive statistics that presented the means and standard deviations of all variables were calculated. An independent sample t-test, paired-sample ttest, and one-way ANOVA, along with the post-hoc test, were used to discover the differences in participants' performance on the productive and receptive collocation tests. The (t) and sig. (2-tailed) were pointed out to determine the significance of the differences. part 4 will include discussion and interpretation of these results.

\section{Discussion And Conclusion}

This section presents a discussion of the results of the study reported in part 3. It begins with interpretations of the findings of the study. Each research question and its results will be provided, followed by a comparison to previous studies. Additionally, the section presents a discussion of the pedagogical implications for female/male learners and continues with the limitations of this study. Finally, it concludes by offering suggestions and recommendations for further research. 


\subsection{Interpretation of the Research Questions}

The overall purpose of the current study was to assess the performance of Arabic-speaking learners of English as a second/foreign language on tests evaluating their use of English collocational knowledge. The study examines the L2 knowledge of collocations in relation to the effect of the learners' language environment (female/male), productive and receptive knowledge, and types of collocations (verb-noun, adjective-noun, and verb-preposition). In particular, the four tests were designed to address the following research questions:

1. Is there a significant difference in the collocational competence of Arabic-speaking advanced learners of English in female environments when compared to those studying in male environments?

2. Is there a significant difference between the participants' productive and receptive knowledge of collocations? 3. Is there a significant difference between the participants' performance on the verb-noun, adjective-noun, and verb-preposition collocation tests?

\subsubsection{The role of the learning environment on the knowledge of collocations}

The first question asked related to whether the educational learning environment, female versus male, had an effect on the learners' knowledge of collocations. To answer this question, the present author tested two groups of participants: students studying English in Saudi Arabia. The results of the present study revealed that the female learners had significantly higher scores $(M=57.20)$ than the male learners $(M=46.68)$. In other words, the female group answered 59.58\% of the questions correctly, whereas the male group answered only 48.22\% correctly. This finding corroborates the research of Shehata (2008), who reported that female participants (who answered $71.1 \%$ of the questions correctly) outperformed the male participants (who answered $56.6 \%$ of the questions correctly).

However, unlike Shehata's research, where female participants showed more advanced collocational knowledge, this study revealed that both groups performed poorly on the collocational tests. This was consistent with previous research that reported poor knowledge of collocations in female contexts (e.g., Aghbar 1990; Zhang 1993; Gitsaki 1996) and in male contexts (Channell 1981; Hussein 1990; Farghal \& Obiedant 1995; AlAmro 2006).

Overall, in response to the first question, the results indicated that there was a significant difference in the collocational knowledge between the female and male groups. It is thus, evident that being in a native English-speaking environment plays a positive role in acquiring L2 collocations. Therefore, the gap in performance between female and male learners can be attributed to the issue of practicing the target language. In an female educational environment, practicing the language and being involved in everyday activities enables learners to use the newly-acquired collocations in real-life situations. However, this does not seem to be the case in male settings. In addition, a number of collocations are acquired by female learners from their surrounding environment and everyday interactions. In contrast, the male students do not have such an advantage. They interact with everybody in their surrounding environment in their mother tongue. They also tend to forget what they have learned very quickly since they rarely use these words once they leave the classroom.

\subsubsection{The productive and receptive knowledge of collocations}

The issue of the difference between the participants' productive and receptive knowledge of collocations is the second aspect of the current study. A cursory look at the results indicates that collocational mismatches were frequent in the participants' answers, both productively and receptively. This is a finding consistent with previous research, such as reported by Bonk (1995) and Al-Amro's (2006). As with those studies, the participants' knowledge of collocations was not considered to be proficient. According to Al-Amro (2006), this is hardly surprising given the idiosyncratic nature of collocation knowledge and that the teaching of collocations in female/male classrooms is often neglected. Furthermore, L2 teachers are focused on giving students synonyms rather than providing them with the appropriate collocations to be used in certain contexts. In addition, the heavy emphasis on synonyms without directing students' attention to the restrictions related to the use of these words may affect the naturalness of communication and can lead to misunderstanding.

In response to the second question, which asked if there is a significant difference between the participants' productive and receptive knowledge of collocations, the data revealed a significant difference. The learners' receptive knowledge of collocations (73\% of their correct answers) was broader than their productive knowledge (33.51\%). This was consistent with Shehata's (2008) study, which found that the subjects were able to judge the correctness of the target collocations in the receptive test (74\%); however, they had difficulties producing the target collocations in the productive test (42\%). This finding is not surprising because evidence shows receptive knowledge typically precedes productive mastery. Nevertheless, in Al-Amro's (2006:iv) study, the participants were more accurate in the productive test than in the receptive test. Although this finding is inconsistent with the present study, Al-Amro reported that "it was due to the fact that the collocations included in the receptive test were of lower frequency than the other collocations in the productive test." 


\subsubsection{Types of collocations}

The current study also explores the differences between participants' productive scores on three categories of collocations: verb-noun, adjective-noun, and verb-preposition. The purpose was to identify which collocation type is easiest to acquire. The results revealed that participants received far better scores on the verbnoun collocation test $(M=9.1)$ than on the adjective-noun $(M=3.39)$ and verb-preposition $(M=3.67)$ collocation tests. This supports the study's third hypothesis and is also consistent with the Shehata's (2008) findings, which Shehata attributes to the emphasis on verbs, rather than adjectives in classrooms in general, and on vocabulary lists.

Interestingly, these results support Channell's conclusions (1981), which shows learners' difficulty in producing acceptable adjective-noun collocations (score of $40 \%$ ) despite their familiarity with the target words included in the test. Participants in this study scored only $21.23 \%$ on the adjective-noun collocation test.

Unlike Bonk's (1995) work, which demonstrated that verb-preposition collocations were easy, this study indicates that verb-preposition collocations are also difficult to deal with (score of 23\%). From the researcher's teaching experience, this finding is hardly surprising because Arab-speaking learners of English, who lack L1 verb-preposition collocations, have a tendency to avoid using phrasal verbs (verb-preposition structure) and substitute them with one-word equivalents (Ben Duhaish 2008).

\subsection{Pedagogical implications}

As with previous studies on collocations, this study demonstrated a consensus in L2 learners' lack of collocational knowledge. The results make apparent a need for more attention to the teaching of collocations. Thus, the following suggested pedagogical implications can serve as a framework for teaching collocation.

Since the educational language environment plays an important role in learning collocations, as shown in this study, it may be useful to employ authentic texts in the teaching of collocations in an male context. Such texts seem to offer a richer environment for exposure to collocations than in typical male textbooks where the input is modified. "When students see words in authentic contexts, they learn how the words function and what their typical collocations are" (Burger \& Gallina 2008:7).

The inadequate proficiency in the production of collocations, as shown in this study, calls for a more constructive, instructional focus on collocations. A mixture of approaches, such as explicit and implicit, is essential to generate a productive learning environment. There are various kinds of activities and exercises that can enhance and develop students' productivity skills, such as telling or writing stories of their own past and then highlighting the collocations used. Additionally, teachers can use "collocational grids" or "brainstorming" in which students are provided with words and then asked to list all the acceptable collocates present. It is also very useful to focus on collocations that have no equivalent in the students' first language.

Based on the findings of the present study, more attention should be given to the teaching of adjectivenoun and verb-preposition collocations. These have proven to be challenging to the students. For example, this can be accomplished by training students to observe and note the specific types of collocations found during reading and then integrate them in sentences.

In general, this study helped prove the necessity of incorporating the teaching of collocations into the female/male curriculum for developing students' English proficiency. L2 teachers should introduce collocations to raise students' awareness of the importance of this phenomenon. Instructors should demonstrate the idiosyncratic nature of collocations as well as the distinctions among them. For instance, when a student questions the difference between wound and injury, teachers usually try to provide definitions to such pairs. However, this is not a complete explanation of the terms and can lead to problems. Hence, it is best to use the collocational fields of the two words to reveal differences in usage. For example English speakers say stab wound rather than stab injury and internal injuries rather than internal wounds (Lewis 2000). Moreover, the need to develop strategies for the acquisition of collocations is very important. Students can be taught to observe collocations and practice using them in either spoken or written forms outside of the classroom. In addition, one way to improve students' knowledge of collocations is to encourage them to use English collocation dictionaries whenever they are uncertain about the usage of a particular word.

\subsection{Limitations of the study}

Although the study adequately addressed the research questions of this thesis, there are a number of limitations:

1. The present study did not use a pre-test to determine participants' familiarity with the collocations. This is very important because one can claim the participants' poor knowledge of collocations results from them not understanding the meaning of the individual words rather than the target collocations.

2. This study was restricted to only three types of collocations and thus does not capture the participants' overall knowledge of collocations. Examining more types and considering other aspects of collocations, such as high/low frequency, may yield different results. 
3. The study was based on a small number of selected collocations (46) and a population sample of 68 participants. More items and a larger population would make it more feasible to generalize the findings.

4. The female participants' degree of exposure to the English language was not recorded. This may have had an impact on the study results because some participants in the advanced level may have just arrived in the United States and thus would not have been fit for the current study.

In conclusion, it is hoped that these limitations will inspire researchers to improve this study or develop better measurements in the future. To further this study and provide direction in this promising field, suggestions for future research are presented in the following section.

\subsection{Suggestions for future research}

As stated earlier, collocations play a vital role in many aspects of language acquisition, comprehension and use. Yet the field of collocations is still in its infancy, and much remains to be learned about the nature of collocations, such as L1 interference, collocational strategies, the acquisition of collocations, the effect of explicit and implicit approaches on the learning of collocations, and the development of collocational proficiency. Therefore, further research on collocations is clearly needed. The current study has yielded some interesting findings, however, they are not conclusive. For the results to be generalized, a replication of this study with a larger and equally tested or evaluated population, more items, and a variety of collocation types is needed.

Conducting a pre-test to determine participants' familiarity with the target collocations is highly recommended. Moreover, a similar study should be conducted on university students (rather than an intensive English program students) whose English proficiency is more advanced, in both the female and male settings. This can be accomplished through using different proficiency tests such as TOFEL, IELTS, or the English language admission proficiency test. However, the same test should be used on both groups to increase the test reliability. Future studies should also consider using a translation task in addition to the present study to obtain a comparison between the free production and the cued production of collocations.

\subsection{Conclusion}

Previous research on collocations has reflected on L2 learners' inadequate proficiency of producing and recognizing collocations. Motivated by this, the present study sought to investigate the productive and receptive knowledge of the collocation of Arabic-speaking learners of English in female and male contexts. The results of the data supported all the hypotheses of the study. It was found that the language environment had an effect on the acquisition of collocations, as manifested by the female participants' better performance. Also, the participants' receptive collocational knowledge was broader than their productive collocational knowledge. Moreover, participants did not seem to have difficulty with verb-noun collocations; however, adjective-noun and verb-preposition collocations were very challenging and much more difficult.

In summary, the results showed that collocations present a source of difficulty for English language learners. Therefore, collocations need more attention from L2 curriculum designers and teachers.

\section{References}

[1]. Aghbar, A. (1990). Fixed expressions in written texts: implications for assessing writing sophistication. Paper presented at a meeting of the English Association of Pennsylvania State System Universities.

[2]. AL-Amro, M. (2006). Saudi learners' knowledge and its relationship to their vocabulary size and writing quality. Unpublished thesis, Colorado State University, Colorado.

[3]. Al-Zahrani, M. (1998). Knowledge of English lexical collocations among male Saudi college students majoring in English at a Saudi university. Unpublished doctoral dissertation, Indiana University of Pennsylvania, Pennsylvania.

[4]. Bahumaid, S. (2006). Collocations in English-Arabic translation. Babel, 52, 133-152.

[5]. Ben Duhaish, F. (2008). "Looking into" ESL/EFL Arab learners' avoidance of phrasal verbs. Unpublished thesis, Colorado State University, Colorado.

[6]. Benson, M., Benson, E., \& Ilson, R. (1986). The BBI combinatory dictionary of English. Amsterdam: John Benjamins Publishing Company.

[7]. Bentivogli, L., and Pianta, E. (2003). Beyond lexical units: Enriching wordnets with phrasets. In proceedings of the research note sessions of the 10th conference of the European chapter of the association for computational linguistics (EACL 'OS), 67-70. Budapest, Hungary, April 2003.

[8]. Biskup, D. (1992). L1 influence on learners' renderings of English collocations: A Polish/German empirical study. In P.J.L. Arnaud \& H. Bejoint (Eds.), Vocabulary and applied linguistics (pp. 85-93). London: Macmillian.

[9]. Bonk, W. (1995). Investigating collocational ability among ESL learners. Unpublished thesis. University of Hawai'i.

[10]. Bonk, W. (2000). Testing ESL learners' knowledge of collocations. (ERIC Document Reproduction Service No. ED 442309)

[11]. Brown, D. (1974). Advanced vocabulary teaching: The problem of collocation. RELC Journal, 5(2), 1-11.

[12]. Burger, S. \& Gallina, J. (2008). Teaching and assessing academic vocabulary based on the academic word list. Contact, 34 (2) 1-80.

[13]. Channell, J. (1981). Applying semantic theory to vocabulary teaching. ELT Journal, 35 (2), pp. 115-122.

[14]. Conklin, K., \& Schmitt, N. (2007). Formulaic sequences: Are they processed more quickly than nonformulaic language by native and nonnative speakers? Applied Linguistics, 28, 1-18. 
[15]. Cowie, A. (1988). Stable and creative aspects of vocabulary use. In Carter, R. and McCarthy, M. (eds), Vocabulary and Language Teaching. Harlow: Longman.

[16]. Cruse, D. (1986). Lexical semantics. Cambridge, Cambridge University Press.

[17]. Decarrico, J. (2001) "Vocabulary Learning and Teaching" in M. Celce-Murcia (ed.) (2001) Teaching English as a Second or Foreign Language (3rd ed), Heinle \& Heinle: Boston. 285-300.

[18]. Elkhatib, A.S.A. (1984). A Classification of the lexical problems of EFL/ESL Students. (New York, U.S., Reports Research/Technical)

[19]. Farghal, M, \& Obiedant, H. (1995). Collocations: a neglected variable in EFL. IRAL, 33(4), 315-331.

[20]. Fillmore, C. (1979). On fluency. In C. Fillmore, D. Kempler \& W.S.Y. Wang (eds). Individual differences in language ability and language behavior. New York: Academic, pp. 85-101.

[21]. Fontenelle, T. (1994). What on earth are collocations: an assessment of the ways in which certain words co-occur and others do not. English Today ,10(4), 42-48.

[22]. Gitsaki, C. (1996) The Development of ESL Collocational Knowledge, Ph.D. thesis, Center for Language Teaching and Research, The University of Queensland, Brisbane, Australia.

[23]. Gitsaki, C. (1999). Second language lexical acquisition: A study of the development of collocational knowledge. Bethesda, MD: International Scholars Publications.

[24]. Hodne, L. (2009). Collocations and Teaching: Investigating word combinations in two English textbooks for Norwegian upper secondary school students. Universitetet i Bergen.

[25]. Howarth, P. (1998). Phraseology and second language proficiency. Applied Linguistics, 19(1), 24-44.

[26]. Hsu, J. (2002). Development in collocational proficiency in a workshop on English for general business purposes for Taiwanese college students. Unpublished doctoral dissertation, Indiana University of Pennsylvania, Pennsylvania.

[27]. Hussein, R. (1990). Collocations: The missing link in vocabulary acquisition amongst English foreign learners. In J. Fisiak (ed.), Papers and studies in contrastive linguistics. The Polish-English contrastive project (Vol. 26, pp. 123-136). Pozan: Adam Mickiewicz University.

[28]. Katz, J. J. \& Fodor, J. A. (1963) 'The structure of a semantic theory. Language 39, 170-210.

[29]. Kim, D. H. (2009). A study on the use of lexical collocations of Korean heritage learners: identifying the sources of errors. Unpublished thesis, University of Sothern Colifornia, Colifornia.

[30]. Laufer, B. (1988). What percentage of text-lexis is essential for comprehension? In C. Lauren \& M. Nordmann (Eds.), Special language: From humans thinking to thinking machines (pp. 316-323). Clevedon, UK: Multilingual Matters.

[31]. Lehrer, A. (1974). Semantic fields and lexical structure. Amsterdam: North-Holland publishing Company.

[32]. Lewis, M. (2000). Teaching collocation: Further developments in the lexical approach. Language Teaching Publications.

[33]. Li, C. (2005): A study of collocational error types in ESL/EFL college learners' writing. M.A. Thesis. Ming Chuan University, Taiwan.

[34]. Lien, H. (2003). The effect of collocation instruction on the reading comprehension of Taiwanese college students. Unpublished doctoral dissertation, Indiana University of Pennsylvania, Pennsylvania.

[35]. Ma, Q. (2009). Second Language Vocabulary Acquisition. New York, Bern, Berlin, Brussels, Frankfurt am Main, Oxford, Wien: Peter Lang Publishing Group.

[36]. Martyńska, M. (2004). Do English language learners know collocations? Investigationes Linguisticae,11. Retrieved May 1, 2007 from http://www.staff.amu.edu.pl/*inveling/pdf/malgorzata_martynska_inve11.pdf

[37]. McCarthy, M. (1990) Vocabulary. Oxford: Oxford University Press.

[38]. McIntosh, A. (1961). Patterns and ranges. Language, 37, 325-37.

[39]. Milton, J. (2009). Measuring second language vocabulary acquisition. Bristol, England: Multilingual Matters.

[40]. Miyakoshi, T. (2009). Investigating ESL learners' lexical collocations: The acquisition of verb+ noun collocations by Japanese learners of English. University of Hawai'i at Manoa, Honolulu, Hawai'i.

[41]. Nation, P. (2001). Learning vocabulary in another language. Cambridge: Cambridge University Press.

[42]. Nattinger, J. (1980). A lexical phrase grammar for ESL. In TESOL Quarterly 14, 337-44.

[43]. Nattinger, J. (1988) "Some current trends in vocabulary teaching", in R. Carter \& M. McCarthy (Eds.) Vocabulary and Language Teaching, London \& New York: Longman; 62-82.

[44]. Nattinger, J. \& DeCarrico, J. (1992). Lexical phrases and language teaching. Oxford University Press, Oxford.

[45]. Nesselhauf, N. (2005). Collocations in a learner corpus. Amsterdam: Benjamins.

[46]. Peters, A. (1983). The units of language acquisition. Cambridge: Cambridge University Press.

[47]. Richards, J. (1976). The role of vocabulary teaching. TESOL Quarterly 10, 77-89.

[48]. Richards, J., \& Rodgers, T. (2001). Approaches and methods in language Teaching (2nd ed.). Cambridge: Cambridge University Press.

[49]. Robins, R. (1967). A short history of linguistics. London: Longman.

[50]. Schmitt, N. (2000). Vocabulary in language teaching. Cambridge: Cambridge University Press.

[51]. Shehata, A. (2008). L1 Influence on the Reception and Production of Collocations by Advanced ESL/EFL Arabic Learners of English. Published thesis. The College of Arts and Sciences of Ohio University, Ohio.

[52]. Sung, J. (2003). English lexical collocations and their relation to spoken fluency of adult non-native speakers. Unpublished doctoral dissertation, Indiana University of Pennsylvania, Pennsylvania.

[53]. Webb, S., \& Kagimoto, E. (2009). The effects of vocabulary learning on collocation and meaning. TESOL Quarterly, 43, 55-77.

[54]. Wray, A. (2002). Formulaic Language and the Lexicon. Cambridge: Cambridge University Press.

[55]. Yorio, C. (1980). Conventionalized language forms and the development of communicative competence. TESOL Quarterly, 14(4), 433-442.

[56]. Zhang, X. (1993). English collocations and their effect on the writing of native and non- native college freshmen. Unpublished doctoral dissertation, Indiana University of Pennsylvania, Pennsylvania.

[57]. Zimmerman, C. (1997). Historical trends in second language vocabulary instruction. In J. Zughoul M. \& Abdul-Fattah, H. (2003). Collocational strategies of Arab learners of English: A study in lexical semantics. Retrieved from ERIC database. 


\section{APPENDIX I: FILL-IN-THE-BLANK TEST \\ Please respond to the following: \\ Part 1:}

Put the verb which best completes the sentence in the blank. Spelling and grammar are not counted, only your choice of words. Use the first letter as a clue. You have 10 minutes.

EXAMPLE: My teacher was disappointed because I didn't do my homework.

1. It's true that we $g$ weight when we eat more than we can burn off.

2. Governments should t the necessary actions to stop global warming.

3. Inborn abilities always $h$ an effect on what we become.

4. Tom's wife g birth to a son yesterday.

5. She usually s a lot of her time reading.

6. The robbery $t$ place at about 3:30 a.m. yesterday.

7. It will d you good to get out of the house very often.

8. Do you think there is a chance that John will $\mathrm{c}$ his mind?

9. It usually t time to change laws.

10. Parents can $\mathrm{p}$ a role in preventing childhood obesity.

11. The lantern was knocked over and the barn c fire.

12. Don't lie, just t the truth!

13. Could you $\mathrm{k}$ an eye on my bag while I go to the toilet?

14. Last July, Mike $m$ the mistake of going to work on a strike day.

15. What difference does it $\mathrm{m}$ if your friend does not have a car?

16. This book describes ten ways to $t$ advantage of the web.

Part2:

Put the adjective which best completes the sentence in the blank. Spelling and grammar are not counted, only your choice of words. Use the first letter as a clue. You have 10 minutes.

EXAMPLE: When she's tired, she really loves to drink strong tea.

1. Are you having s thoughts about coming to Brighton with me?

2. If you do not take the s cut, it is four miles further.

3. The most dominant p parties in the US are the Democratic and the Republican.

4. Today is your 1 chance to submit your final project.

5 . The majority of people die of o age all over the world.

6. McDonald's is the largest $\mathrm{f}$ food advertiser in the US.

7. The boxer gave him a b eye, so he was taken to hospital.

8. The term $\mathrm{f}$ arts is used to refer to the visual arts such as painting and architecture.

9. Although there were no executions, the state reestablished c punishment in 1982.

10. The forecaster predicted $\mathrm{h}$ rain and strong winds during the afternoon storm.

11. Everyone knows that a little w lie is sometimes necessary in a time of crisis.

12. China hopes to grow its $m$ class to more than half of its total population by 2020 .

$13 \mathrm{He}$ had a $\mathrm{n}$ escape from gunfire.

14. An a volcano is expected to erupt quite soon.

15. Politicians are trying to influence $\mathrm{p}$ opinion on the topic.

16. Coca Cola mainly produces s drinks rather than juices or water.

Part3:

Fill in the blanks with prepositions to complete the sentence. The meaning of the expression is in parentheses at the end of the line. You have $\mathbf{1 0}$ minutes.

EXAMPLE: Hey that's a nice leather jacket; mind if I try it on ? (to wear)

1. We ordered wine and two appetizers and the bill came \$78. (to total)

2. Don't worry you can depend me. (to trust)

3. I'm sorry I can't drive all the way to school, but I can drop you at the bus stop if you like. (to drive someone to a place)

4. It's taken me more than a month to get this cold. (to recover) 
5. They set a bomb in the busy market place. (to cause explode)

6. The criminals who held the Bank of Hawaii last week still have not been caught. (to rob)

7. Sylvester Stallone's new movie is scheduled to come on April 19. (to appear)

8. My doctor told me to give alcohol and cigarettes if I want to stay health. (to stop using)

9. Patty was Ron's girlfriend for a long time, but they broke two weeks ago. (to end a relationship)

10. Many of the birds in the area were killed by local hunters. (to exterminate)

11. We've been talking about this for over an hour now; let's move to another topic. (to go)

12. My father never studied English formally, he just picked it when he came here ten years ago. (to learn)

13. Other kids always pick her because she is so overweight. (to tease)

14. He takes his father, he has the same hair and eyes. (to look like)

15. She told me that she wanted to go to Alaska and work on fishing boat on the summer, but I talked her of it. (to convince not to do)

Grandfather has been feeling very sad, let's go to his house and cheer him (to make happier)

\section{APPENDIX II: ACCEPTABILITY JUDGMENT TEST}

Decide whether the underlined part of the sentence is acceptable or not. Circle the NUMBER corresponding to the strange part of the sentence. You have 25 minutes.

EXAMPLE: $\square$. When she's tired, she really loves to drink heavy tea. (The number is circled since the sentence is unacceptable)

1. The dentist will fix my artificial teeth.

2. After the death of his son, Mark had a heart attack.

3. I've finished writing up the minutes of the meeting; would you please look out them and see if I've made any mistakes?

4. Eating soup at the start of a meal fills the stomach.

5. Are you having second thoughts about coming to Brighton with me?

6. My doctor told me to give up alcohol and cigarettes if I want to stay health.

7. There was a wide public desire to read good novels.

8. Tom's wife gave birth to a son yesterday.

9. Mark dreams off becoming a soccer player.

10. If you do not take the short cut, it is four miles further.

11. The poor peasant was murdered in hot blood.

12. Sylvester Stallone's new movie is scheduled to come out on April 19.

13. It will do you good to get out of the house very often.

14. The most dominant political parties in the US are the Democratic and the Republican.

15. He refused to comment in the problem.

16. She excused herself and went upstairs to put her makeup.

17. The robbery took place at about 3:30 a.m. yesterday.

18. The criminals who held up the Bank of Hawaii last week still have not been caught.

19. Today is your last chance to submit your final project.

20. Students are expected to do more efforts to pass the exam.

21 . They were asked to participate on the interviews.

22. What difference does it make if your friend does not have a car?

23. The majority of people die of old age all over the world.

24. They set off a bomb in the busy market place.

25. Last July, Mike made the mistake of going to work on a strike day.

26. The growing generation is the nation's hope for building a happy future.

27. Applicants who filled about the questionnaire were then chosen randomly.

28. John left his mind in the days before his suicide.

29. Although no executions took place, the state reestablished capital punishment in 1982.

30. It's taken me more than a month to get over this cold.

31. The lantern was knocked over and the barn caught fire.

32. You need to run more vitamins and minerals in your diet.

33. The students are protesting off the invasion.

34. McDonald's is the largest fast food advertiser in the US.

35. Don't lie, just tell the truth! 
36. I'm sorry I can't drive all the way to school, but I can drop you off at the bus stop if you like.

37. He had a narrow escape from gunfire.

38. The boxer gave him a black eye, so he was taken to hospital.

39. Jackson apologized up his rude behavior.

40. This book describes ten ways to take advantage of the web.

41. Coca Cola mainly produces soft drinks rather than juices or water.

42. Don't worry you can depend on me.

43. Ok, I think I will put the risk.

44. The term fine arts is used to refer to the visual arts such as painting and architecture.

45. He will suffer about studying too little.

46. Could you keep an eye on my bag while I go to the toilet?

47. The heavy traffic made me late for my appointment.

48. We ordered wine and two appetizers and the bill came to $\$ 78$.

49. Fixing false limbs has now become possible.

50. Inborn abilities always have an effect on what we become.

51. His mother accused him on eating the entire cake.

52. The forecaster predicted heavy rain and strong winds during the afternoon storm.

53. Governments should take the necessary actions to stop global warming.

54. Patty was Ron's girlfriend for a long time, but they broke up two weeks ago.

55. This tourist speaks broken English.

56. She usually spends a lot of her time reading.

57. Many of the birds in the area were killed off by local hunters.

58. Everyone knows that a little white lie is sometimes necessary in a time of crisis.

59. We've been talking about this for over an hour now; let's move on to another topic

60. Parents can play a role in preventing childhood obesity.

61. Politicians are trying to influence public opinion on the topic.

62. My father never studied English formally, he just picked it up when he came here ten years ago

63. It's true that we gain weight when we eat more than we can burn off.

64. The student studies hard to get success.

65. Other kids always pick on her because she is so overweight.

66. China hopes to grow its middle class to more than half of its total population by 2020 .

67. It usually takes time to change laws.

68. He takes after his father, he has the same hair and eyes.

69. It was mainly a quiet residential area with many family homes and a few businesses.

70. Do you think there is a chance that John will change his mind?

71. She told me that she wanted to go to Alaska and work on fishing boat on the summer, but I talked her out of it.

72. A wide imagination stimulates the thinking process and the ability to create.

73. If you take my advice, you'll stop seeing him.

74. Grandfather has been feeling very sad, let's go to his house and sheer him up.

75. An active volcano is expected to erupt quite soon. 